\title{
Research on Microgrid Scheduling Based on Improved Crow Search Algorithm
}

\author{
Zhifei Zhang ${ }^{\mathbb{D}}$, Cai Zhao $\mathbb{D}$, Danfeng Chen, and An Wen \\ School of Automation, Foshan University of Science and Technology, Foshan 528000, China \\ Correspondence should be addressed to Cai Zhao; 644197884@qq.com
}

Received 8 October 2021; Revised 16 December 2021; Accepted 18 December 2021; Published 31 January 2022

Academic Editor: Faroque Azam

Copyright (c) 2022 Zhifei Zhang et al. This is an open access article distributed under the Creative Commons Attribution License, which permits unrestricted use, distribution, and reproduction in any medium, provided the original work is properly cited.

Considering the characteristics of distributed power in microgrid, in order to maximize the advantages of distributed power generation technology in economy, environment, and energy, a multiobjective dispatching model of microgrid is proposed under the condition of satisfying system constraints and considering the operating costs and environmental costs of microgrid. The crow search algorithm (CSA) has the advantages of less parameter setting, simple implementation, and strong optimization ability and is often used in theoretical analysis and practical engineering applications. However, its disadvantage is that crows only search for candidate solutions according to their own experience, and their development ability is poor, especially for solving high-dimensional functions. In order to overcome these shortcomings, an improved crow search algorithm (CSA-PSO) is proposed based on the particle swarm optimization (PSO) algorithm. The two main improvements are as follows: (1) in order to avoid the blind selection of crow in search, the global optimal solution is adopted to modify the solution search equation to guide the search of new candidate solutions, so as to improve the development ability; (2) introducing a levy flight strategy to improve the single search mechanism of the CSA. In order to verify the performance of the CSA-PSO algorithm, 17 benchmark functions are simulated with other intelligent algorithms. The results show that the CSA-PSO algorithm has a good optimization effect in search accuracy, convergence speed, and robustness. Finally, this algorithm and other five algorithms are applied to the optimal scheduling problem of microgrid. By solving the objective function, the optimal scheduling output scheme of each distributed power supply is obtained. By using the CSA-PSO algorithm, the total operating cost of microgrid is reduced by at least $21.5 \%$, which further verifies the effectiveness of the CSA-PSO algorithm.

\section{Introduction}

Due to environmental problems and energy crisis, renewable energy and other distributed energy sources are developing rapidly all over the world. However, due to the intermittency and uncertainty of renewable energy output power, largescale distribution power generation connected to the grid presents many challenges such as power quality and system stability [1]. The emergence of microgrid brings new and effective technologies to solve the current problems. Microgrid is a new type of distributed energy organizational structure, which is considered to be an effective platform for integrating renewable energy, enabling the renewable energy system to access the distribution network more conveniently, and realizing the integrated operation of distributed power generation to load [2-4]. As one of the core technologies of microgrid, optimal scheduling has laid a solid foundation for the development and promotion of microgrid, and has an important engineering value.

The solution of optimal scheduling of microgrid is essentially a nonlinear optimization problem with multiobjective and multiconstraint conditions $[5,6]$. In view of the optimization scheduling problem of microgrid, scholars at home and abroad have carried out a lot of research work, and intelligent algorithms instead of traditional optimization algorithms are generally adopted recently. At present, common intelligent algorithms include particle swarm optimization [7], gray wolf algorithm [8], evolution algorithm 
[9], and self-learning discrete Jaya algorithm [10], which are widely used. It provides a new idea to solve the problem of microgrid operation optimization.

The crow search algorithm is a metaheuristic algorithm proposed by Iranian scholar A. Asarzadeh in 2016 [11]. The CSA shows good performance in multiobjective, multiconstraint, and nonlinear optimization, and its fitness function has few constraints, simple structure, simple coding, and fast convergence speed. Therefore, the CSA is widely popular in the optimal operation of microgrid. In the literature [12], the crow search algorithm is used to solve the optimal size and location of capacitors in the distribution network. The experimental results show that the CSA has more accurate solution than other search methods. Literature [13] applied the CSA to reactive power optimization scheduling problem, and the CSA performed better than the comparison algorithm in the test of a benchmark test system, successfully solving the reactive power optimization scheduling problem. Literature [14] uses the CSA to optimize conductor selection in a radial distribution network, and the experimental results show that the CSA performs better than the traditional optimization algorithm. However, the primary crow search algorithm has some defects compared with other swarm intelligence algorithms, including low search accuracy, high possibility of entering local optimum, and premature convergence, especially for multidimensional optimization problems. Many improvements have been made to overcome the shortcomings of the CSA [15-20]. In literature [15-17], the chaos theory is used to improve the master crow search algorithm, and it is used to solve multiobjective optimization problems. The above measures improve the optimization performance of the crow search algorithm to a certain extent, but all the improvement work is focused on the standard CSA based on single memory search mode. They did not take into account other searching behaviors in the crows' intelligent behavior. When solving complex and high-dimensional problems, there are still some defects such as slow convergence speed, low solution accuracy, and insufficient robustness. Literature [18] adds adaptive inertia weights to the original CSA position update mechanism. In the initial stage of the search, larger inertia weights can enhance the global search capability, while in the final stage, the reduction of inertia weights can enhance the local exploration capability, avoiding repeated jumps in position caused by over-searching, so that the crow can quickly move to the extreme value point. The test results show that the optimization performance and convergence speed of the improved algorithm are significantly improved. The test results show that the optimization performance and convergence speed of the improved algorithm are improved obviously. Literature [19] proposed a rough crow search algorithm (RCSA), which combined the CSA with rough search mechanism (RSS), which effectively solved the problems of inaccuracy and roughness of available information when searching for global optimal solutions of highdimensional optimization problems. When realizing optimization, the CSA was used to search for approximate solutions of global optimization problems, and then, RSS was introduced to improve accuracy. The test results show that the RCSA performs better in calculation accuracy. Literature [20] proposed a crow search algorithm (NICSA) based on neighborhood search of a noninferior solution set. This algorithm makes crows automatically select memory search mode or neighborhood search mode in the evolution process through the determinant of noninferior solution. Through this strategy, the local search and global search of the algorithm become more balanced. Function tests show that the algorithm is superior to the CSA in search accuracy and convergence speed.

To sum up, the ultimate purpose of many improved algorithms is to improve the search accuracy and global optimization ability of the algorithm, and speed up the convergence of the algorithm. In this article, an improved crow search algorithm (CSA-PSO) is proposed based on the optimization mechanism of particle swarm optimization (PSO). The two main improvements are as follows: (1) in order to avoid the blind selection of crow in the search, the global optimal solution is adopted to modify the solution search equation to guide the search of new candidate solutions, so as to improve the development ability; and (2) the single search mechanism of CSA is improved by introducing the levy flight strategy to avoid falling into local optimum effectively.

This article is organized as follows: Section II "Problem Formulation" describes the objective function and power constraints. Section III studies different operation strategies of energy storage devices. Section IV discusses the improvement and verification of the algorithm and its application in microgrid. Finally, Section V "Conclusion" summarizes the research results of the study.

\section{Microgrid Optimization Model}

2.1. Distributed Generation Model. The structure of a microgrid generally consists of distributed energy sources, energy storage devices, controllers, and loads. In order to take full advantages of microgrid, scholars around the world have devoted significant efforts on the optimal operation of microgrid [21]. Microsources are divided into the following two types according to whether their output power can be controlled:

(1) One is uncontrollable microsource such as photovoltaic cells (PVs) and wind turbines (WTs).

(2) The other is controllable microsource including microturbines (MTs), internal combustion engine (ICEs), and fuel cells (FCs).

A typical microgrid system architecture is shown in Figure 1 .

2.2. Objective Function. With the deepening of research, the decision-making of power generation scheduling changes from a single consideration of economic benefits to the consideration of the coordination between economic benefits and environmental protection, and thus. the objective function becomes a multiobjective problem, which is 


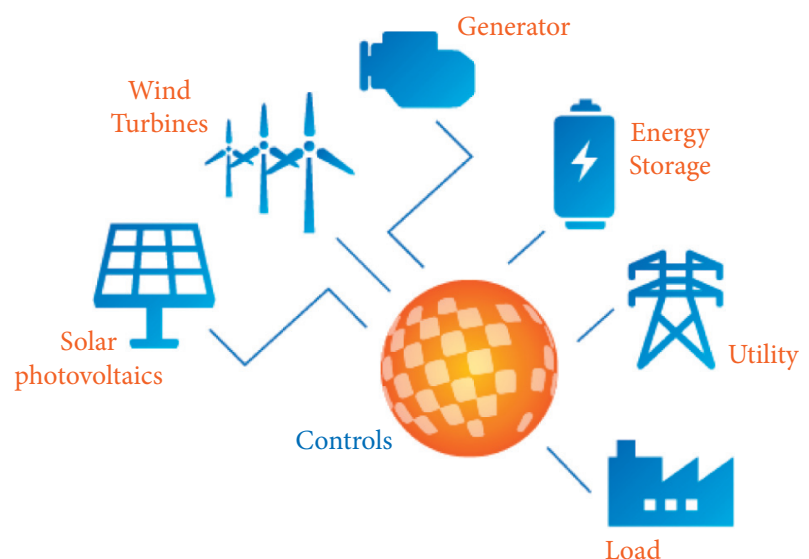

Figure 1: Microgrid structure.

mutually restricted and coordinated between the two. The general model is shown in the following formula:

$$
\begin{aligned}
\min F(x) & =\min \left(\left[f_{1}(x), f_{2}(x), \ldots, f_{n}(x)\right]^{T}\right), \\
& \text { s.t. } \\
x & \in \Omega, \\
G(x) & =0, \\
H(x) & \leq 0,
\end{aligned}
$$

where $x$ is the optimization variable; $F_{\mathrm{i}}$ is the ith optimization objective; $\Omega$ is the solution space of feasible solutions; and $\mathrm{G}(x)$ and $\mathrm{H}(x)$ are the constraints of the equality and inequality in the feasible region.

Based on the above general model, this article only considers the lowest economic cost and the best environmental benefit as the objective function, where the economic cost includes the fuel cost, operation and maintenance cost, and interaction cost with the main network; the environmental cost is the treatment cost of pollutants $\left(\mathrm{CO}_{2}, \mathrm{NOx}\right.$, $\mathrm{SO}_{2}$ ) emitted during the operation of the micropower source.

$$
F=\min \left(\varphi F_{1}+\mu F_{2}\right),
$$

where $F$ is the total operating cost; $F_{1}$ and $F_{2}$ are the economic cost and environmental treatment cost respectively; and both $\phi$ and $\mu$ are taken as 0.5 .

- Objective function 1: Economic costs

$$
\min F_{1}(x)=\sum_{t=1}^{T}\left[\sum_{i=1}^{N}\left(C_{i, f} P_{i, t}+C_{i, m} P_{i, t}\right)+C_{G r i d, t} P_{G r i d, t}+C_{B T, t} P_{B T, t}\right]
$$

where $T$ is a dispatch period; $N$ is the type of distributed power source; $C_{i, f}, C_{i, m}$ are the fuel coefficient and operation and management cost of each micropower, respectively; $P_{i, t}$ is the output power of the ith micropower source; $C_{G r i d, t}, C_{B T, t}$ are the electricity price at time $T$ and the operation and management cost of the battery, respectively; and $P_{G r i d, t}, P_{B T, t}$ are the interaction power with the grid and the output power of the battery at moment $t$, respectively.

- Objective function 2: Environmental costs

$$
\min F_{2}(x)=\sum_{t=1}^{T}\left(\sum_{i=1}^{I} \alpha_{i}\left(\sum_{j=1}^{N} \beta_{j i} P_{j}^{t}+\beta_{\text {Gridi }} P_{\text {Grid }}^{t}\right)\right)
$$

where $\alpha_{i}$ is the cost of treatment of pollutant $i$ type; $\beta_{j i}$ is the emission factor of pollutant category $i$ for the jth micropower source; $P_{j}$ is the output power of the micropower source; $\beta_{\text {Gridi }}$ is the emission factor of pollutant typei for the main grid; and $P_{\text {Grid }}$ is the output power of the main grid.

\subsection{Constraints}

(1) Power balance constraint

$$
P_{d}^{t}=\sum_{i=1}^{N} P_{G i}^{t}+P_{G r i d}^{t}
$$

where $P_{d}^{t}$ is the system load in the time period $t ; P_{G i}^{t}$ is the output power of each microsource; and $P_{\text {Grid }}^{\mathrm{t}}$ is the interaction power with the main network.

(2) Constraint on the power output of each micropower source

$$
P_{t}^{\min } \leq P_{G i} \leq P_{t}^{\max }
$$

where $P_{t}^{\min }, P_{t}^{\max }$ are the upper and lower limits of the output power of the micropower supplyi, respectively.

(3) Power constraints between microgrid and main grid

$$
P_{\text {Grid }}^{\min } \leq P_{\text {Grid_t }} \leq P_{\text {Grid }}^{\max },
$$


where $P_{G r i d}^{\min }, P_{\text {Grid }}^{\max }$ are the upper and lower power limits for the interaction between the microgrid and the main grid, respectively; if $P_{\text {Grid }}^{\min }<0$, it indicates that the microgrid system can output power to the main grid.

(4) Battery operating constraints

$$
P_{B T}^{\min } \leq P_{B T}^{i} \leq P_{B T}^{\max }
$$

where $P_{B T}^{\min }, P_{B T}^{\max }$ are the upper and lower power limits of the battery, respectively.

\section{Improvement of Crow Search Algorithm}

3.1. Principle of the Crow Search Algorithm. The CSA was proposed by an Iranian scholar A. Asarzadeh in 2016 [11]. Suppose there is D-dimensional search space, the number of crows is $\mathrm{N}$, and the position vector of crow $i$ in time in the search space determines $x^{i, \text { iter }}(i=1,2 \ldots, N$; iter $=1,2, \ldots$. iter $\left._{\max }\right)$, if and only if $x^{i . i t e r}=\left[x_{1}^{i, i t e r}, x_{2}^{i, i \text { iter }}, \ldots . . x_{d}^{i, \text { iter }}\right]$. And it stands when the maximum number of iterations is reached. Each crow hides its food and remembers the location of the food. Suppose that at the iteration, the crow $j$ wants to visit its hidden food location $m^{j, i t e r}$. And the crow $i$ decides to follow the crow $j$ to approach the crow $j$ 's food hiding place. At this point, the following two states may occur:

- State 1: the crow $j$ is unaware that the crowi is following behind, at which point the crowi updates its position to

$$
x^{i, i t e r+1}=x^{i, i t e r}+r_{i} \times f l^{i, i t e r} \times\left(m^{j, i t e r}-x^{i, i t e r}\right),
$$

where $r_{i}$ is the random number between $[0,1] ; f l^{i, i t e r}$ is the distance flown by the crow $i$ in theiter th iteration; and $m^{j, i t e r}$ is the location of the best food remembered by the crow $j$ in the iter th iteration.

- State 2: The crow $j$ realizes that the crowi is chasing it. In order to make the location of the hidden food undetected, the crow $j$ will find a random location to trick the crowi.

In summary, states 1 and 2 are represented as follows: $\left\{\begin{array}{lr}x^{i, \text { iter }+1}=x^{i, \text { iter }}+f l^{i, \text { iter }} \times\left(m^{j, \text { iter }}-x^{i, \text { iter }}\right), & r_{i} \geq A P, \\ \text { a random position, } & \text { otherwise }\end{array}\right.$

where $A P$ represents the perceived probability.

3.2. Analysis of Defects in the Crow Search Algorithm. The CSA has the advantages of simple operation, few parameters, and strong search capability, but it lacks diversity and poorly developed performance when searching for candidate solutions based only on its own experience, which is especially obvious for the optimization of high-dimensional functions, and the search is updated iteratively according to equation (10). Figure 2 shows the schematic diagram of the CSA search with the following limitations:

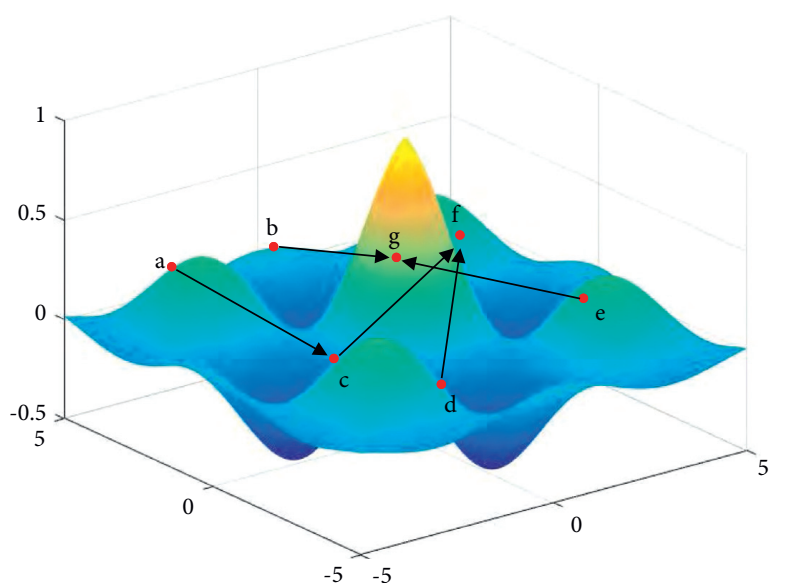

FIgURe 2: Diagram of the crow search algorithm. (a) During the search, an individual crow will start a random search in a sector centered on the current location. The sector area consists of the memory position, the current position, and its difference. Due to this unimodal search method, the crow's flight activity lacks locomotion and diversity. As can be seen from Figure 2, the crow lacks its exploitation capability (the ability to search for candidate solutions) and it cannot efficiently search for other possible global optimum regions (e.g., g), which can easily fall into local optimum. (b) CSA is a single way to improve the diversity of the algorithm by generating probabilistic random solutions through its own experience, which leads to a high probability of entering a local optimum, premature maturity, and other drawbacks, especially for multidimensional optimization problems.

3.3. Basic Particle Swarm Algorithm. PSO is a metaheuristic algorithm first proposed by James Kennedy and Russell Eberhardt in 1995 for solving nonlinear optimization problems [7]. In PSO, we start with a random set of candidate solutions, called a "swarm" of particles. Each particle can be visualized as a point in a D-dimensional space, where $D$ is the dimension of the candidate solution. Each particle then searches the space (and thus explores different possible solutions) based on its position and velocity. The motion of a particle is influenced by three components-its "momentum," its optimal position (the position with the highest value of particle fitness, called the local optimal position), and the most suitable position for the particle (called the global optimal position). This facilitates the particles to move closer to the optimal solution. Figure 3 shows the schematic diagram of the particle swarm algorithm for finding the optimum.

The particle swarm algorithm is more capable of exploitation, and the new candidate solution is to find the global optimal solution by sharing information about itself and all particles within the population, and in the next iteration, the particles decide the next movement based on the guidance of the global optimal solution.

Suppose there is a D-dimensional space, the individual extremum of particle $X_{i}=\left(X_{i 1}, X_{i 2}, X_{i 3} \ldots X_{i D}\right)$, the individual extremum of particle $i$ is denoted as $P_{\text {besti }}=\left(p_{i 1}, p_{i 2}, p_{i 3} \ldots p_{i D}\right)$, and $V_{i}=\left(V_{i, 1}, V_{i, 2}, V_{i, 3} \ldots V_{i, D}\right)$ is the velocity vector of the particle $i$, that is, the distance the particle travels, $P_{G b e s t}=\left(p_{G 1}, p_{G 2}, p_{G 3} \ldots p_{G D}\right)$ is the global 


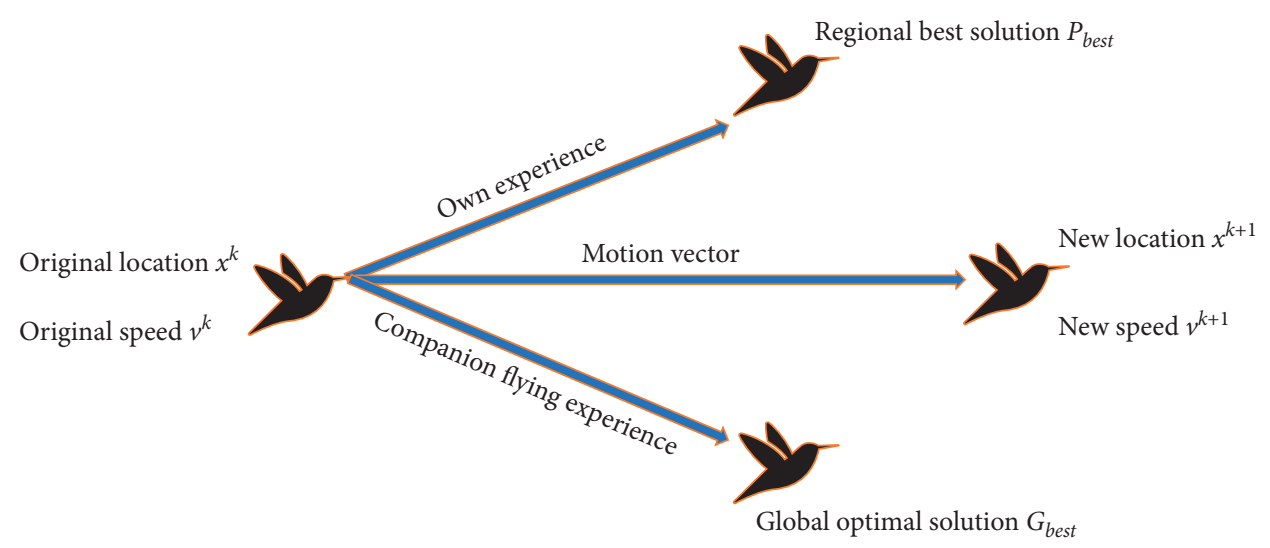

FIGURE 3: Schematic diagram of the particle swarm algorithm for finding the optimal solution.

optimal position searched by the particle, and the particle adjusts its motion in the next step according to Equations (11)-(12), thus continuously iterating toward the optimal solution.

$$
\begin{aligned}
v_{i}^{k+1} & =v_{i}^{k}+c_{1} r_{1} *\left(p_{\text {besti }}-x_{i}^{k}\right)+c_{2} r_{2} *\left(p_{\mathrm{Gbest}}-x_{i}^{k}\right), \\
X_{i}^{k+1} & =X_{i}^{k}+v_{i}^{k+1},
\end{aligned}
$$

where $V_{i}$ and $X_{i}$ are the velocity and position of the particle, respectively; $c_{1}$ and $c_{2}$ are learning factors; $r_{1}$ and $r_{2}$ are random numbers between $[0,1] ; P_{\text {besti }}$ and $P_{G \text { Gest }}$ are the individual optimal extrema and the global optimal extrema.

\subsection{Principle of Improved Crow Search Algorithm.} Through the above analysis of advantages and disadvantages of the CSA algorithm, in order to further improve the performance of the CSA algorithm, after knowing the mechanism of the particle swarm optimization algorithm, this article mainly discusses the improvements made by CSA: (1) to avoid the crow choice blindness during the search, each a crow in the search for the optimal solution, and the other partner's information sharing in the population, thus in the global optimal solution found in the population as a whole has the optimal individual extremum, population according to the information update the raven iteration. We modify the solution search equation by using the global optimal solution to guide the search of new candidate solutions, so as to improve the development ability. The crow search algorithm retains the crow of the main features of the search algorithm, but the crow search algorithm and particle swarm are different obviously, improve the crow search algorithm for the solution to the old and new candidate solutions, and then save the better solution, and the particle swarm is not involved in the selection process. Secondly, the single search mechanism of the algorithm is improved by introducing the levy flight strategy. According to the random update strategy adopted by the standard crow search algorithm in state 2 , in the case of no leader, it is possible to be around the poor solution when searching for an optimal solution, thus falling into local optimal. Based on this situation, the levy flight search strategy is introduced. Levy flight is a random walk process, which involves a large number of short walks at short distances, followed by long walks at long distances. Levy flight is applied to the swarm intelligence optimization algorithm, which ensures that individuals will not stay in the local range when they move by means of long-distance migration in the early stage of search, thus enlarging the search range and effectively jumping out of the local optimum. The algorithm tends to converge after the close walk.

\subsubsection{Global Optimal Solution Guiding Search Mechanism.}

When the crow is in state 1 , the new candidate solution for crow optimization is generated by moving the old solution toward (or away from) another solution randomly selected from the population. However, the probability of a randomly chosen solution being a good solution is the same as that of a randomly chosen solution being a bad solution, so the new candidate is not necessarily a better solution than the previous one. In this way, the algorithm will fall into the local optimum and fail to find the global optimal solution, while the PSO algorithm determines the next motion according to the guidance of the global optimal solution during particle iteration. Based on this idea, we modify the solution search equation by using the global optimal solution to guide the search of new candidate solutions, so as to improve the search ability. The update mechanism is as follows:

$$
\begin{aligned}
x^{i, \text { iter }+1}= & x^{i, \text { iter }}+r_{i} \times f l^{i, \text { iter }} \times\left(m^{j, \text { iter }}-x^{i, \text { iter }}\right)+r_{i} \times f l^{i, \text { iter }} \\
& \times\left(P_{\text {iter }}-x^{i, \text { iter }}\right),
\end{aligned}
$$

where $r_{i}$ is the random number between[0,1]; $P_{\text {Gbest }}$ is the global best position; $f l^{i, i t e r}$ denotes the flight distance of the crow $i$ in the iter th iteration; and $m^{j \text {,iter }}$ denotes the position of the best food remembered by the crow $j$ in the iter th iteration.

3.4.2. Levy Flight Strategy. When the crow is in state 2, it will randomly choose a new position to confuse the stalker, which may lead to blindness in searching for optimal direction in the absence of a leader. Based on this defect, the 
levy flight search strategy is introduced to replace random search. Levy flight is a random walk process, which contains a large number of short walk and long walk. Levy flight is applied to the swarm intelligence optimization algorithm, which ensures that individuals will not stay in the local range when they move by means of long-distance migration in the early stage of search, thus enlarging the search range and effectively jumping out of the local optimum. In the later stage, the close walk makes the algorithm tend to converge, and the improved formula is as follows:

$$
\begin{aligned}
x^{i, \text { iter+1 }} & =x^{i, \text { iter }} \times(1+\operatorname{Levy}(n)), \\
\operatorname{Levy}(n) & =a \times \frac{r_{a} \times \sigma}{|\gamma|^{(1 / \beta)}}, \\
\sigma & =\left(\frac{\Gamma(1+\beta) \times \sin (\pi \beta / 2)}{\Gamma(1+\beta / 2) \times \beta \times 2^{(\beta-1 / 2)}}\right)^{(1 / \beta)},
\end{aligned}
$$

where $r_{a}$ is a random number in the interval $(0,1) ; \gamma, \sigma$ obeys a normal distribution; $n$ is the dimension; $a$ is the step size factor to be 0.01 , and $\beta$ the constant is to be 1.5 ; and $\Gamma$ is the standard Gamma function.

In summary, the improved update formula is as follows:

$$
x^{i, \text { iter }+1}= \begin{cases}x^{i, \text { iter }+r_{i} \times f l^{i, \text { iter }} \times\left(m^{j, \text { iter }}-x^{i, i t e r}\right)+} r_{i} \times f l^{i, \text { iter }} \times\left(P_{\mathrm{Gbest}}-x^{i, \text { iter }}\right), & r_{i} \geq A P, \\ x^{i, \text { iter }} \times(1+\operatorname{Levy}(n)), & \text { otherwise }\end{cases}
$$

where $r_{i}$ is the random number between $[0,1] ; P_{\text {Gbest }}$ is the global best position; $f l^{i, i t e r}$ denotes the flight distance of the crow $i$ in the iter th iteration; and $m^{j, \text { iter }}$ denotes the position of the best food remembered by the crow $j$ in the iter th iteration;

3.4.3. Algorithm Flow. The CSA-PSO algorithm flow is shown in Figure 4. The specific pseudocodes of the CSA-PSO algorithm are as follows (Algorithm 1):

\section{Experimental Simulations}

In order to verify the effectiveness of CSA-PSO, 17 benchmark functions from references [22-24] are tested in this article and solved with the crow search algorithm (CSA) [11], particle swarm algorithm (PSO) [7], gray wolf algorithm (GWO) [8], particle swarm genetic algorithm (PSOGA) [25], and integrated learning particle swarm algorithm (CLPSO) [26]for the 17 benchmark functions.

4.1. Baseline Functions. The sequence numbers, expressions, dimensions, search ranges, and theoretical optima of the 17 test functions are shown in Table 1. The test functions are diverse and can reflect the search performance of the algorithm more objectively, fairly, and comprehensively. The 17 benchmark functions can be divided into three types: (1) $f_{1} \sim f_{7}$ are single-peaked high-dimensional functions to study the search accuracy of the algorithm; (2) $f_{8} \sim f_{11}$ are multimodal high-dimensional functions with many local extremes for testing the global search performance of the algorithm; and (3) $f_{12} \sim f_{17}$ are multimodal low-dimensional functions.
4.2. Analysis of the Results of CSA-PSO Compared with Other Intelligent Algorithms. The parameters were selected by experimental comparison and are shown in Table 2. Also, for each test function, 3000 evaluations were performed and each algorithm was run independently 30 times. Four metrics, optimum, mean, worst, and variance, were used to measure the performance of the various algorithms, and the experimental statistics are shown in Tables 3 to 5 .

From Table 3, it can be seen that CSA-PSO has good performance for solving single-peaked high-dimensional functions, where for functions $f_{1}, f_{2}, f_{3}, f_{4}, f_{5}$, and $f_{7}$, it outperforms the other 5 intelligent algorithms in terms of both optimal, worst, mean, and variance values, with strong robustness. For function $f_{6}$, the PSOGA shows good performance, indicating that PSOGA is suitable for solving such function problems, whereas the CSA-PSO algorithm is not effective for solving such problems. For the overall comparison, CLPSO has the worst overall performance, larger variance, weaker stability, and larger variance.

From Table 4, CSA-PSO has good performance for solving multimodal high-dimensional functions. CSA-PSO easily finds its global optimum in solving two functions, $f_{8}$. $f_{9}$ and $f_{11}$, and outperforms the other 5 intelligent algorithms in terms of optimum, worst-case, mean, and variance, and has good stability. In solving the $f_{10}$ function, CSA-PSO, although it can find the global optimum, the variance is larger compared to CSA-PSO and slightly more unstable than PSOGA. Overall, CSA-PSO has a clear advantage over the other 5 algorithms when it comes to such functions.

From Table 5, it can be seen that CSA-PSO has the same good performance for solving multimodal low-dimensional functions, especially for functions $f_{12}, f_{15}, f_{16}$, and $f_{17}$, the 
Input: Population size $N$, maximum number of iterations iter $_{\max }$, flight distance $f l$, the probability of consciousness $A P$.

(1) Initialize the memory of each crow.

(2) Evaluate fitness function.

(3) while iter $\leq$ iter $_{\text {max }}$ do

(4) for $i=1 ; i<N ; i++$ do

(5) Randomly selected crows.

(6) Defining the probability of consciousness.

(7) if $r_{i}>A P$ then

(8) $x^{i, i t e r+1}=x^{i, i t e r}+r_{i} \times f l^{i, i t e r} \times\left(m^{j, i t e r}-x^{i, i t e r}\right)+r_{i} \times f l^{i, i t e r} \times\left(P_{G b e s t}-x^{i, i t e r}\right)$

(9) else

(10) $x^{i, i t e r+1}=x^{i, i t e r} \times(1+\operatorname{Lev} y(n))$

(11) end if.

(12) end for.

(13) Check the feasibility of the new location

(14) Evaluate the new location of the crow and update the memory

(15) end while.

Algorithm 1: Proposed crow search algorithm.

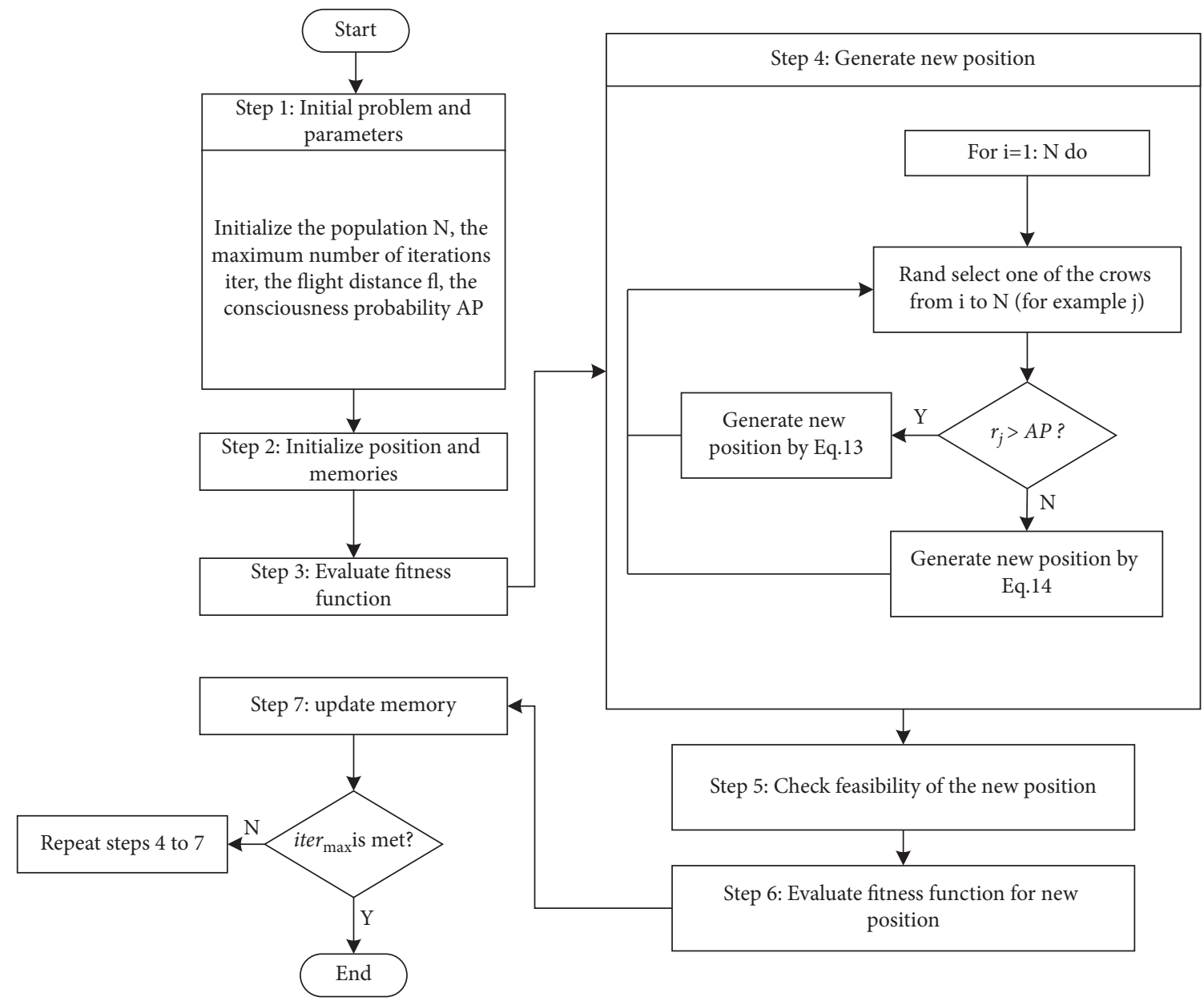

FIgURE 4: Flowchart of the CSA-PSO algorithm.

mean, optimum, worst value, and variance are better than other intelligent algorithms. This shows that the search accuracy and stability of CSA-PSO are better. And for $f_{13}$ and $f_{14}$, CSA-PSO is slightly lower than CLPSO in all aspects, but on the whole, CSA-PSO has stronger search performance and robustness.

Figures 5 to 21 represent the optimal convergence graphs of the 6 intelligent algorithms for solving the 17 test 
TABle 1: Standard test functions.

\begin{tabular}{|c|c|c|c|c|c|}
\hline $\begin{array}{l}<!-\text { Col Count: } \\
6>\text { Type }\end{array}$ & $\begin{array}{c}\text { Serial } \\
\text { number }\end{array}$ & Function & Dimension & Scope & optimum \\
\hline \multirow{7}{*}{ I } & $f_{1}(x)$ & $f(x)=\sum_{i=1}^{D} x_{i}^{2}$ & 30 & {$[-100,100]$} & 0 \\
\hline & $f_{2}(x)$ & $f(x)=\sum_{i=1}^{D}\left|x_{i}\right|+\prod_{i}^{D}\left|x_{i}\right|$ & 30 & {$[-10,10]$} & 0 \\
\hline & $f_{3}(x)$ & $f(x)=\sum_{i=1}^{D}\left(\sum_{j=1}^{i} x_{i}\right)^{2}$ & 30 & {$[-100,100]$} & 0 \\
\hline & $f_{4}(x)$ & $f(x)=\max _{i=1}\left\{\left|x_{i}\right|\right\}$ & 30 & {$[-100,100]$} & 0 \\
\hline & $f_{5}(x)$ & $f(x)=\sum_{i=1}^{n-1}\left[100\left(x_{i+1}^{i=1}-x_{i}^{2}\right)^{2}+\left(1-x_{i}\right)^{2}\right]$ & 30 & {$[-30,30]$} & 0 \\
\hline & $f_{6}(x)$ & $f(x)=\sum_{i=1}^{D}\left(\left|x_{i}+0.5\right|\right)^{2}$ & 30 & {$[-100,100]$} & 0 \\
\hline & $f_{7}(x)$ & $f(x)=\sum_{i=1}^{D} i \cdot x_{i}^{4}+$ random $(0,1)$ & 30 & {$[-1.28,128]$} & 0 \\
\hline \multirow{4}{*}{ II } & $f_{8}(x)$ & $f(x)=\sum_{i=1}^{D} x_{i} \cdot \sin \left(\sqrt{\left|x_{i}\right|}\right)$ & 30 & {$[-500,500]$} & $411.99^{*} \mathrm{n}$ \\
\hline & $f_{9}(x)$ & $f(x)=\sum_{i=1}^{n}\left(x_{i}^{2}-10 \cdot \cos \left(2 \cdot \pi \cdot x_{i}\right)+10\right)$ & 30 & {$[-5.12,5.12]$} & 0 \\
\hline & $f_{10}(x)$ & $f(x)=-20 \exp \left(-0.2 \sqrt{\frac{1}{d} \sum_{i=1}^{d} x_{i}^{2}}\right)-\exp \left(\frac{1}{d} \sum_{i=1}^{d} \cos \left(2 \pi x_{i}\right)\right)+20+e$ & 30 & {$[-32,32]$} & 0 \\
\hline & $f_{11}(x)$ & $f(x)=\frac{1}{4000} \cdot \sum_{i=1}^{n} x_{i}^{2}-\prod_{i=1}^{n} \cos \frac{x_{i}}{\sqrt{i}}+1$ & 30 & {$[-600,600]$} & 0 \\
\hline \multirow{6}{*}{ III } & $f_{12}(x)$ & $f(x)=\sum_{i=1}^{11}\left[a_{i}-\left(x_{1}\left(b_{i}^{2}+b_{i} x_{2}\right) / b_{i}^{2}+b_{i} x_{3}+x_{4}\right)\right]$ & 4 & {$[-5,5]$} & 0.9980 \\
\hline & $f_{13}(x)$ & $f(x)=-\sum_{i=1}^{4} c_{i} . \exp \left[-\sum_{i=1}^{4} a_{i j}\left(x_{j}-p_{i j}\right)\right]^{2}$ & 3 & {$[0,1]$} & -1.0316 \\
\hline & $f_{14}(x)$ & $f(x)=-\sum_{i=1}^{4} c_{i} \cdot \exp \left[-\sum_{i=1}^{6} a_{i j}\left(x_{j}-p_{i j}\right)\right]^{2}$ & 6 & {$[0,1]$} & -3.980 \\
\hline & $f_{15}(x)$ & $f(x)=-\sum_{i=1}^{5}\left[\left(x-a_{i}\right)\left(x-a_{i}\right)^{T}+c_{i}\right]^{-1}$ & 4 & {$[0,10]$} & -10.7532 \\
\hline & $f_{16}(x)$ & $f(x)=-\sum_{i=1}^{7}\left[\left(x-a_{i}\right)\left(x-a_{i}\right)^{T}+c_{i}\right]^{-1}$ & 4 & {$[0,10]$} & -10.4029 \\
\hline & $f_{17}(x)$ & $f(x)=-\sum_{i=1}^{10}\left[\left(x-a_{i}\right)\left(x-a_{i}\right)^{T}+c_{i}\right]^{-1}$ & 4 & {$[0,10]$} & -10.5634 \\
\hline
\end{tabular}

TABle 2: Parameter settings for each algorithm.

\begin{tabular}{|c|c|}
\hline Algorithm & Parameter \\
\hline CSA [11] & The population size is 50 , the probability of consciousness is 0.2 , and the flying distance is 2 \\
\hline PSO [7] & The population size is $50, c 1=c 2=1.49445$ \\
\hline GWO [8] & Population size is 50 \\
\hline PSOGA [25] & The population size is $50, c 1=c 2=1.49445$ \\
\hline CLPSO [26] & The population size is $50, c 1=c 2=1.49445$ \\
\hline CSA-PSO & The population size is 50 , the probability of consciousness is 0.2 , and the flying distance is 2 \\
\hline
\end{tabular}

TABLE 3: Statistics of $f_{1} \sim f_{7}$ test results.

\begin{tabular}{|c|c|c|c|c|c|c|c|}
\hline Benchmark & Function & CSA [11] & PSO [7] & GWO [8] & PSOGA [25] & CLPSO [26] & CSA-PSO \\
\hline \multirow{4}{*}{$f_{1}(x)$} & Best & $2.2040 E-11$ & $1.3541 E-01$ & $9.3108 E-57$ & $9.7886 E-06$ & $4.5018 E+03$ & $4.7635 E-161$ \\
\hline & Mean & $4.2512 E+02$ & $5.2932 E+02$ & $7.5608 E+02$ & $3.2338 E+00$ & $1.8605 E+04$ & $6.5645 E-155$ \\
\hline & Worst & $2.2396 E+05$ & $1.1946 E+05$ & $1.9910 E+05$ & $14044 E+03$ & $1.5436 E+05$ & $6.0358 E-106$ \\
\hline & Std & $6.0254 E+03$ & $5.1984 E+03$ & $5.2391 E+03$ & $3.4286 E+02$ & $1.6735 E+04$ & $\mathbf{0}$ \\
\hline \multirow{4}{*}{$f_{2}(x)$} & Best & $2.6320 E-19$ & $2.9600 E-13$ & $1.8206 E-107$ & $2.1438 E-13$ & $1.4691 E-05$ & $5.4448 E-215$ \\
\hline & Mean & $3.4047 E+08$ & $3.0928 E+09$ & $1.0527 E+07$ & $2.9940 E-01$ & $6.7898 E+08$ & $6.6238 E-191$ \\
\hline & Worst & $9.9224 E+11$ & $9.2772 E+12$ & $2.2545 E+10$ & $1.4896 E+01$ & $8.2950 E+10$ & $8.2240 E-190$ \\
\hline & Std & $1.1823 E+10$ & $1.6938 E+11$ & $4.4340 E+08$ & $1.3998 E-01$ & $7.3918 E+09$ & $\mathbf{0}$ \\
\hline \multirow{4}{*}{$f_{3}(x)$} & Best & $6.2822 E-58$ & $3.0838 E-46$ & $2.2431 E-321$ & $6.2394 E-53$ & $2.4688 E-17$ & 0 \\
\hline & Mean & $1.1538 E-01$ & $1.8480 E+01$ & $1.4880 E-01$ & $4.5320 E-01$ & $4.1794 E+00$ & $1.8000 E-03$ \\
\hline & Worst & $1.6404 E+02$ & $8.9517 E+01$ & $1.2522 E+02$ & $8.6540 E+01$ & $1.4607 E+02$ & $3.2596 E-00$ \\
\hline & Std & $3.8538 E+00$ & $2.7738 E+01$ & $3.4053 E+00$ & $3.7617 E+00$ & $1.5595 E+01$ & $8.6500 E-02$ \\
\hline \multirow{4}{*}{$f_{4}(x)$} & Best & $2.5246 E-05$ & $6.3481 E-02$ & $6.8418 E-46$ & $1.4422 E-01$ & $1.6408 E+01$ & $\mathbf{0}$ \\
\hline & Mean & $0.7307 E+00$ & $1.9283 E+00$ & $4.7450 E-01$ & $4.7730 E-01$ & $3.5197 E+01$ & $3.4102 E-01$ \\
\hline & Worst & $8.7613 E+01$ & $8.6038 E+01$ & $8.8409 E+01$ & $1.3986 E+00$ & $8.8886 E+01$ & $1.3258 E+00$ \\
\hline & Std & $4.2351 E+00$ & $4.4388 E+00$ & $4.7237 E+00$ & $2.5870 E-01$ & $1.7879 E+01$ & $1.3958 E-01$ \\
\hline \multirow{4}{*}{$f_{5}(x)$} & Best & $2.4191 E+01$ & $2.6202 E+01$ & $2.7124 E+01$ & $2.8704 E+01$ & $3.5616 E+01$ & $2.2728 E+01$ \\
\hline & Mean & $1.6583 E+05$ & $9.8047 E+05$ & $1.4765 E+05$ & $5.7180 E+03$ & $7.1453 E+06$ & $9.1149 E+01$ \\
\hline & Worst & $2.8280 E+08$ & $2.1944 E+08$ & $1.7112 E+08$ & $5.6213 E+06$ & $2.9882 E+08$ & $1.1408 E+03$ \\
\hline & Std & $5.5125 E+06$ & $1.0845 E+07$ & $3.9046 E+06$ & $1.4389 E+05$ & $3.0072 E+07$ & $8.1572 E+01$ \\
\hline
\end{tabular}


TABle 3: Continued.

\begin{tabular}{|c|c|c|c|c|c|c|c|}
\hline Benchmark & Function & CSA [11] & PSO [7] & GWO [8] & PSOGA [25] & CLPSO [26] & CSA-PSO \\
\hline \multirow{4}{*}{$f_{6}(x)$} & Best & $1.6839 E+00$ & $9.4726 E-02$ & $3.6528 E+00$ & $4.9168 E-06$ & $7.0937 E+03$ & $4.2093 E-01$ \\
\hline & Mean & $1.7959 E+03$ & $6.6675 E+02$ & $6.4385 E+02$ & $1.4043 E+01$ & $2.3743 E+04$ & $4.4713 E+01$ \\
\hline & Worst & $1.5811 E+05$ & $1.9438 E+05$ & $1.6579 E+05$ & $7.8471 E+03$ & $1.0617 E+05$ & $1.7041 E+04$ \\
\hline & Std & $9.0603 E+03$ & $7.3068 E+03$ & $6.4798 E+03$ & $2.1541 E+02$ & $1.9884 E+04$ & $6.6766 E+02$ \\
\hline \multirow{4}{*}{$f_{7}(x)$} & Best & $9.0827 E-50$ & $1.2395 E-41$ & $1.15113 E-309$ & $4.4268 E-48$ & $3.4583 E-47$ & $\mathbf{0}$ \\
\hline & Mean & $9.9960 E-02$ & $2.6088 E+01$ & $1.3220 E-01$ & $6.3700 E-01$ & $3.7228 E+00$ & $2.4645 E-03$ \\
\hline & Worst & $1.2187 E+02$ & $1.2162 E+02$ & $1.2901 E+02$ & $1.2677 E+02$ & $1.0238 E+02$ & $2.5632 E+00$ \\
\hline & Std & $2.5274 E+00$ & $3.8778 E+01$ & $3.3568 E+00$ & $6.0112 E+00$ & $1.4134 E+01$ & $5.4560 E-02$ \\
\hline
\end{tabular}

TABLE 4: Statistics of $f_{8} \sim f_{11}$ test results.

\begin{tabular}{|c|c|c|c|c|c|c|c|}
\hline Benchmark & Function & CSA [11] & PSO [7] & GWO [8] & PSOGA [25] & CLPSO [26] & CSA-PSO \\
\hline \multirow{4}{*}{$f_{8}(x)$} & Best & 12555.5 & 12535.6 & 12545.6 & 12456.5 & 12468.5 & 12369.5 \\
\hline & Mean & 15558.5 & 12551.0 & 12556.0 & 12511.5 & 12517.5 & 12369.5 \\
\hline & Worst & 12566.5 & 12566.5 & 12566.5 & 12566.5 & 12566.5 & 12369.5 \\
\hline & Std & 0.6604 & 8.4747 & 1.3525 & 3.8816 & 7.6493 & $\mathbf{0}$ \\
\hline \multirow{4}{*}{$f_{9}(x)$} & Best & $1.6140 E+01$ & $2.8853 E+01$ & 0 & $1.0347 E+02$ & $2.5452 E-04$ & 0 \\
\hline & Mean & $1.7976 E+02$ & $1.2327 E+01$ & $4.8836 E+00$ & $1.1440 E+02$ & $7.4130 E+01$ & $1.5235 E+00$ \\
\hline & Worst & $4.5287 E+02$ & $4.5415 E+02$ & $4.7328 E+02$ & $3.2849 E+02$ & $4.3900 E+02$ & $2.5612 E+02$ \\
\hline & Std & $8.96887 E+01$ & $1.2021 E+02$ & $3.0505 E+01$ & $3.8524 E+01$ & $9.9651 E+01$ & $1.7214 E+01$ \\
\hline \multirow{4}{*}{$f_{10}(x)$} & Best & $2.8422 E-14$ & $1.4211 E-14$ & $7.1054 E-15$ & $1.3404 E+00$ & $1.6343 E-04$ & 0 \\
\hline & Mean & $3.7690 E+00$ & $1.9807 E+00$ & $1.4550 E-01$ & $1.3939 E+00$ & $4.7087 E-00$ & $7.6700 E-02$ \\
\hline & Worst & $2.0908 E+01$ & $2.0739 E+01$ & $2.0708 E+01$ & $3.8946 E+00$ & $2.0778 E+01$ & $1.6260 E+01$ \\
\hline & Std & $2.2036 E+00$ & $2.8738 E+00$ & $1.3664 E+00$ & $2.8720 E-01$ & $6.6027 E+00$ & $8.3530 E-01$ \\
\hline \multirow{4}{*}{$f_{11}(x)$} & Best & 0 & $9.8573 E-03$ & 0 & $3.4417 E-15$ & $1.0697 E-06$ & 0 \\
\hline & Mean & $1.9117 E+00$ & $7.7893 E+00$ & $1.0585 E-00$ & $7.0000 E-01$ & $2.9504 E+01$ & $1.6669 E-01$ \\
\hline & Worst & $6.4092 E+02$ & $6.2316 E+02$ & $6.0532 E+02$ & $8.7530 E-01$ & $6.2665 E+02$ & $6.0398 E-01$ \\
\hline & Std & $2.4669 E+01$ & $5.3623 E+01$ & $1.7231 E+01$ & $3.0700 E+00$ & $9.0822 E+01$ & $2.7957 E+00$ \\
\hline
\end{tabular}

TABLE 5: Statistics of $f_{12} \sim f_{17}$ test results.

\begin{tabular}{|c|c|c|c|c|c|c|c|}
\hline Benchmark & Function & CSA [11] & PSO [7] & GWO [8] & PSOGA [25] & CLPSO [26] & CSA-PSO \\
\hline \multirow{4}{*}{$f_{12}(x)$} & Best & $3.0750 E-04$ & $3.5607 E-04$ & $3.0749 E-04$ & $3.0749 E-04$ & $4.2259 E-04$ & $5.0729 E-04$ \\
\hline & Mean & $9.9225 E-04$ & $8.5372 E-04$ & $4.7058 E-04$ & $3.4391 E-04$ & $7.7928 E-04$ & $5.6262 E-04$ \\
\hline & Worst & $7.4910 E-01$ & $2.4600 E-02$ & $6.3600 E-02$ & $3.2300 E-02$ & $4.0900 E-02$ & $2.4000 E-02$ \\
\hline & Std & $1.4600 E-02$ & $9.0876 E-04$ & $1.3000 E-03$ & $7.2104 E-04$ & $2.2000 E-03$ & $1.0000 E-03$ \\
\hline \multirow{4}{*}{$f_{13}(x)$} & Best & -3.8573 & -3.8628 & -3.8628 & -3.8628 & -3.8628 & -3.4918 \\
\hline & Mean & -3.8567 & -3.8613 & -3.8611 & -3.8602 & -3.8625 & -3.4918 \\
\hline & Worst & -3.6208 & -3.3545 & -3.4566 & -2.7272 & -3.8253 & -3.3487 \\
\hline & Std & $1.0000 E-02$ & $1.9500 E-02$ & $1.2600 E-02$ & $3.6900 E-02$ & $2.1000 E-03$ & $2.6000 E-03$ \\
\hline \multirow{4}{*}{$f_{14}(x)$} & Best & -2.8790 & -3.3220 & -3.1974 & -3.3220 & -3.3220 & -1.7382 \\
\hline & Mean & -2.8193 & -3.2706 & -3.1752 & -3.3091 & -3.3074 & -1.7313 \\
\hline & Worst & -0.9589 & -0.9545 & -1.1668 & -0.3734 & -1.9246 & -1.2739 \\
\hline & Std & $2.0800 E-01$ & $1.4770 E-01$ & $6.6600 E-02$ & $1.5450 E-01$ & $9.6500 E-02$ & $2.3300 E-02$ \\
\hline \multirow{4}{*}{$f_{15}(x)$} & Best & -4.2572 & -10.7532 & -10.7532 & -5.0552 & -10.7532 & -10.7532 \\
\hline & Mean & -3.6754 & -8.7391 & -8.6398 & -5.0488 & -9.7867 & -10.7705 \\
\hline & Worst & -3.0413 & -1.7402 & -0.3004 & -2.3804 & -0.7808 & -0.8964 \\
\hline & Std & $7.2990 E-01$ & $3.1656 E+00$ & $1.6722 E+00$ & $1.0540 E-01$ & $1.3385 E+00$ & $4.7490 E-01$ \\
\hline \multirow{4}{*}{$f_{16}(x)$} & Best & -4.8937 & -10.4029 & -10.4029 & -5.0877 & -10.4029 & -10.4029 \\
\hline & Mean & -4.4672 & -10.1704 & -8.8978 & -5.0482 & -10.0425 & -10.3253 \\
\hline & Worst & -0.6553 & -0.6564 & -0.6910 & -2.4914 & -0.6999 & -1.5442 \\
\hline & Std & $9.0450 E-01$ & $8.8990 E-01$ & $1.7652 E+00$ & $7.1500 E-02$ & $1.4493 E+00$ & $5.822 E-02$ \\
\hline \multirow{4}{*}{$f_{17}(x)$} & Best & -4.7151 & -10.5634 & -10.5634 & -5.1285 & -10.5634 & -10.5634 \\
\hline & Mean & -3.7711 & -9.2562 & -9.4344 & -5.1225 & -10.0107 & -10.4460 \\
\hline & Worst & -5.5075 & -0.7323 & -1.1943 & -2.4080 & -0.7274 & -1.2714 \\
\hline & Std & $8.9630 E-01$ & $2.8824 E+00$ & $1.3167 E+00$ & $9.5100 E-01$ & $1.6650 E+00$ & $5.2630 E-02$ \\
\hline
\end{tabular}




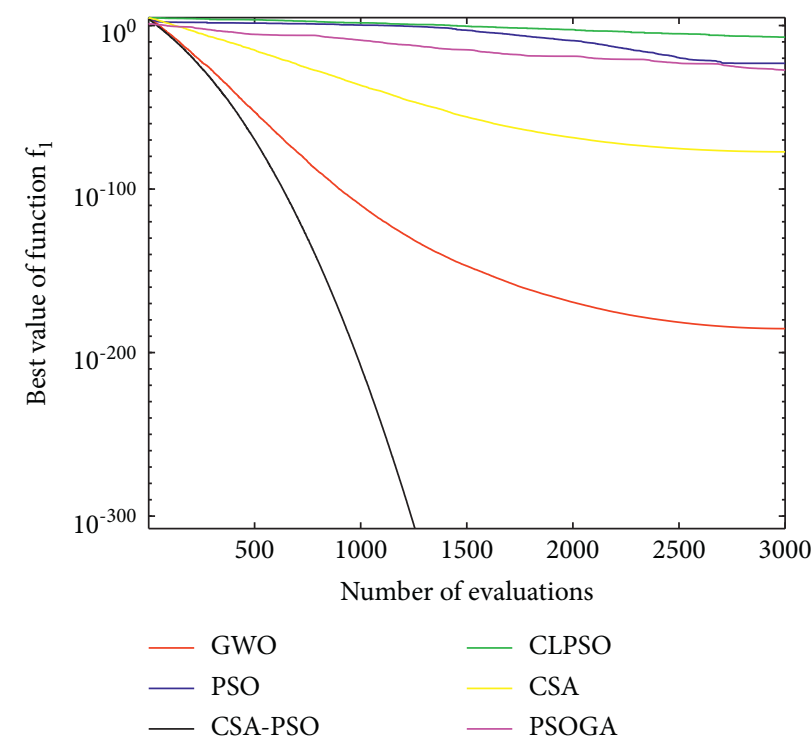

FIgURE 5: Evolutionary curve of fitness values for $f 1$.

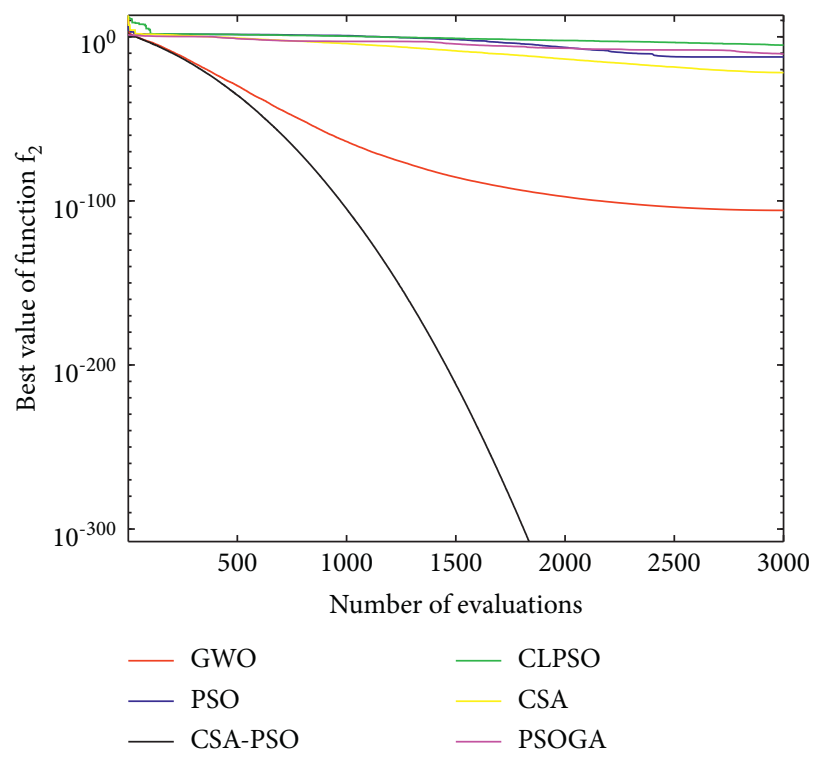

FIGURE 6: Evolutionary curve of fitness values for $f 2$.

functions. From Figures 5-21, it can be seen that CLPSO has the lowest convergence speed but the best search accuracy for the (f) 13 and (f) $)_{14}$ functions, and the convergence speed of the other 5 algorithms subsequently varies with the test function characteristics. The PSOGA also has good convergence performance. However, for the other test functions, the search accuracy of CSA-PSO is significantly higher than the other 5 algorithms except for the (f) $)_{6}$, (f) $)_{13}$, and (f) 14 functions. Therefore, different algorithms have different advantages in terms of convergence speed, but CSA-PSO has a more comprehensive advantage.

In summary, the optimal result statistics of each function are shown in Table 6.

It can be seen from Table 6 that for low-dimensional functions with 30 dimensions, CSA-PSO shows better search results than 5 algorithms except for $f_{6}, f_{13}, f_{14}$. However, the PSOGA has a small solving effect for these three types of functions, indicating that it is suitable for solving such functions. However, in general, the algorithm proposed in this article is obviously higher than the other five algorithms in both search accuracy and convergence algorithm, thus demonstrating the superiority of the algorithm proposed in this article.

4.3. High-Dimensional Function Tests. In order to verify the search performance of CSA-PSO for high-dimensional functions, 11 high-dimensional test functions were also tested independently, including $f_{1}$ to $f_{11}$. Meanwhile, the dimensionality has been changed from 30 to 50 and 100 


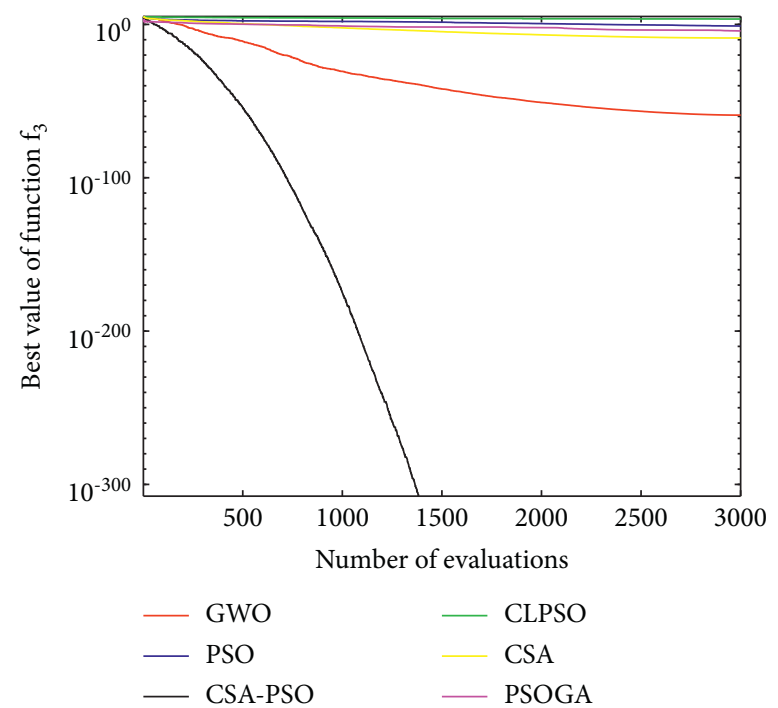

Figure 7: Evolutionary curve of fitness values for $f 3$.

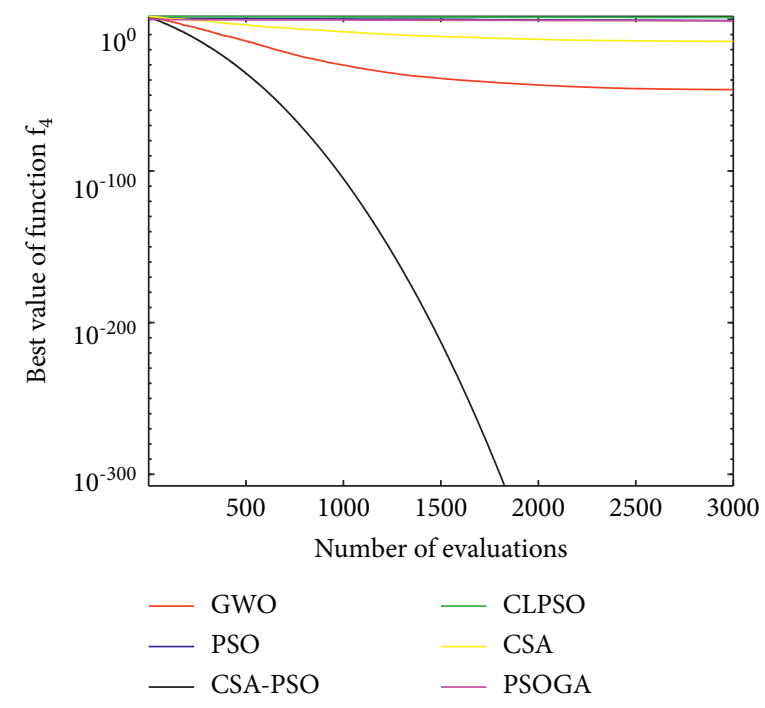

Figure 8: Evolutionary curve of fitness values for $f 4$.

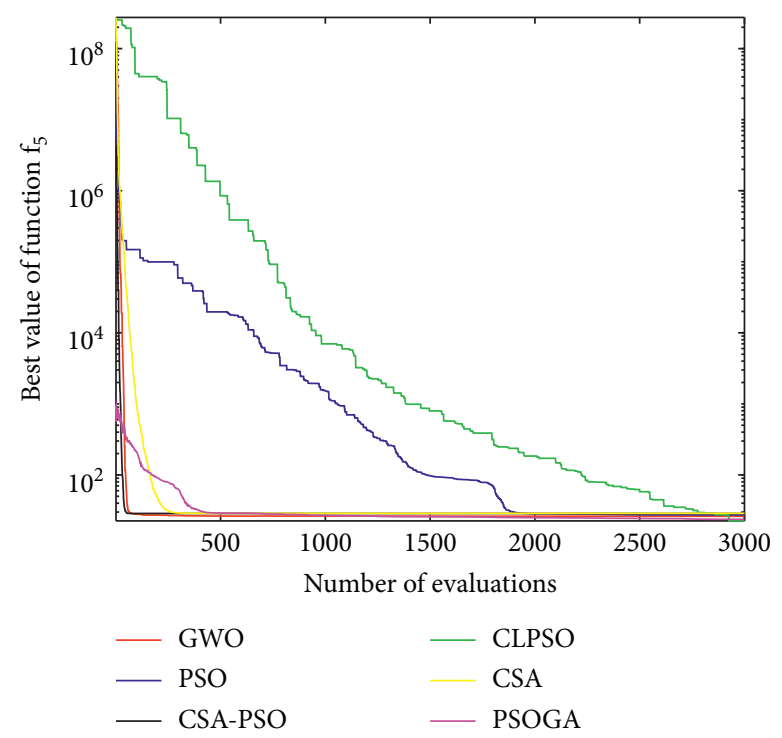

FIgURE 9: Evolutionary curve of fitness values for $f_{5}$. 


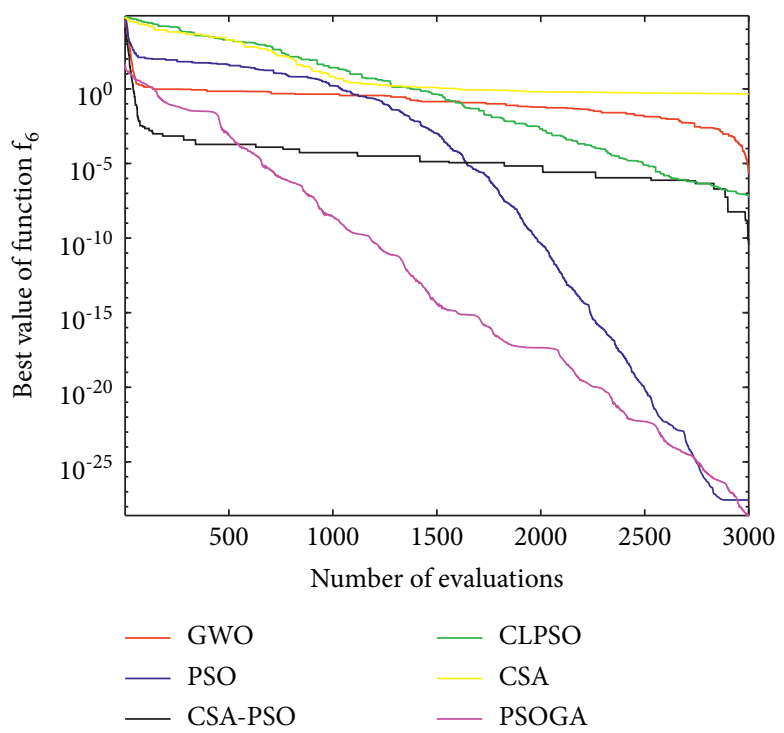

FIGURE 10: Evolutionary curve of fitness values for $f 6$.

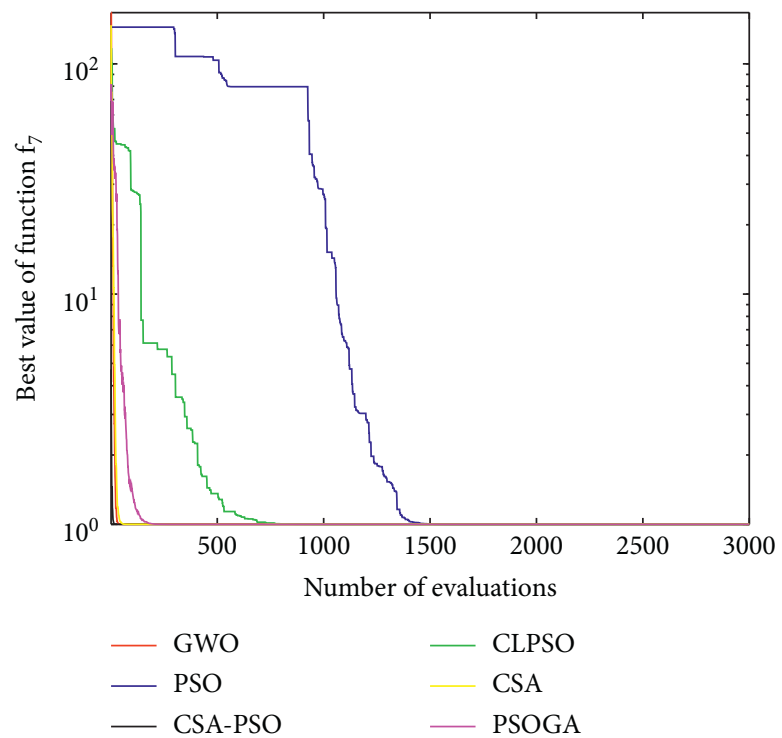

FIGURE 11: Evolutionary curve of fitness values for $f 7$.

dimensions for testing. The parameter settings of each intelligent algorithm are shown in Table 2. The optimal, worst value, mean, and variance of each intelligent algorithm are shown in Table 7.

As can be seen in Table 7, for high-dimensional functions of 50 and 100 dimensions, CSA-PSO shows better search results than the other 5 algorithms, except for $f_{8}$. For $f_{9}$ and $f_{11}$, both CSA-PSO and GWO searched for the global optimum, but for variance and mean, CSA-PSO was more stable. For $f_{8}$, CSA-PSO slightly underperformed PSOGA for 30, 50, and 100 dimensions, but CSA-PSO outperformed PSOGA for best, mean, worst, and variance for the other tested functions. Thus, CSA-PSO has better performance for higher dimensional functions.

\subsection{CSA-PSO-Based Microgrid Energy Dispatch}

4.4.1. Data Underlying the Algorithm. In this article, taking Guangdong as an example and based on the simulation platform, the specific parameters of each micropower supply are shown in Table 8. Pollutant discharge parameters are shown in Table 9, and output power of PV, WT, and load is shown in Figure 22. When connected to the grid, the price of electricity purchase and sale is shown in Figure 23.

4.4.2. Analysis of Results. In this article, the mathematical model is established with the objective function of the lowest economic cost and best environmental benefit, and the microgrid dispatching model is solved using PSO, CLPSO, 


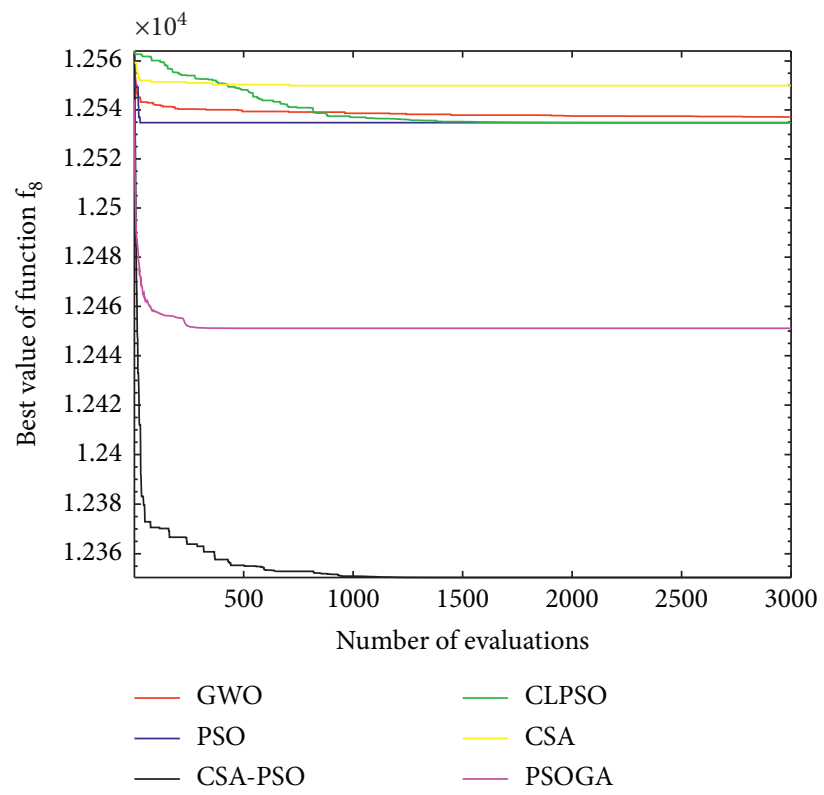

Figure 12: Evolutionary curve of fitness values for $f 8$.

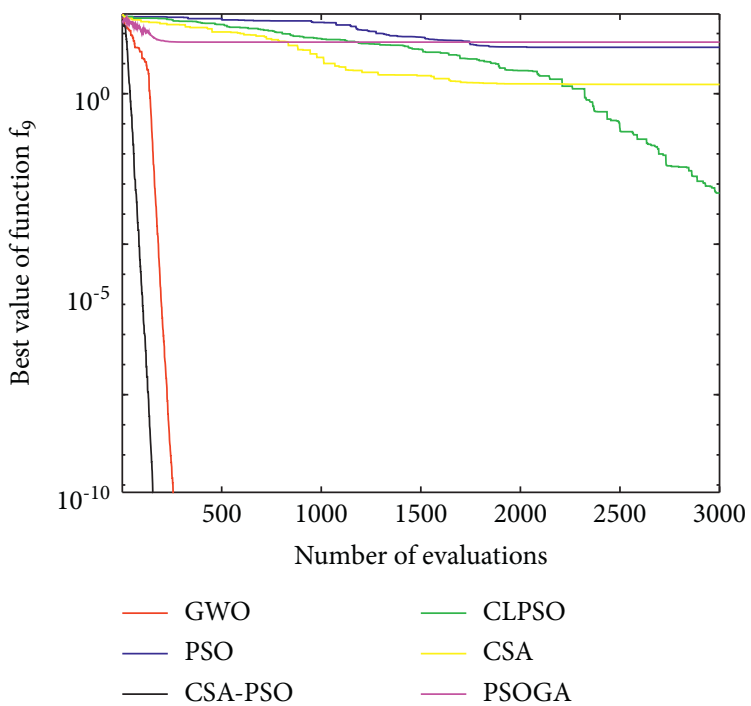

Figure 13: Evolutionary curve of fitness values for $f 9$.

CSA, GWO, PSOGA, and CSA-PSO, and the output of micropower sources is shown in Figure 24.

As can be seen from Figure 24, PV and WT are clean energy, so they are always in full production state. FC has low generation cost, so it always gives priority to output. When the power generation cost of MT is lower than the power purchase cost from 8:00 to 22:00, MT outputs. If MT and FC are at the maximum output power, but still cannot meet the needs of the load, ICE output is considered to meet the needs of the load. BT at 1:00-5:00, when the electricity price is in the trough, it chooses to buy power from the grid and charge the battery for the excess. With the increase of electricity consumption, considering the price of electricity, it will help the power grid to discharge at $10: 00-11: 00,16$ : $00-22: 00$, and $23: 00-00: 00$ to reduce the operation cost.

The comparison of the six intelligent algorithms adopts the same parameter setting for the test: particle swarm size is 50 , and the maximum iteration number is 3000 . The CSA-PSO algorithm begins to converge at about 100 generations, whereas PSOGA, GWO, CLPSO, and other algorithms begin to converge at about 500 generations. It can be seen that the convergence speed of the CSA-PSO algorithm is significantly higher than that of other intelligent algorithms. For the search accuracy of the algorithm, the specific optimization results are shown in Table 10. The results show that the CSA-PSO can find a better solution 


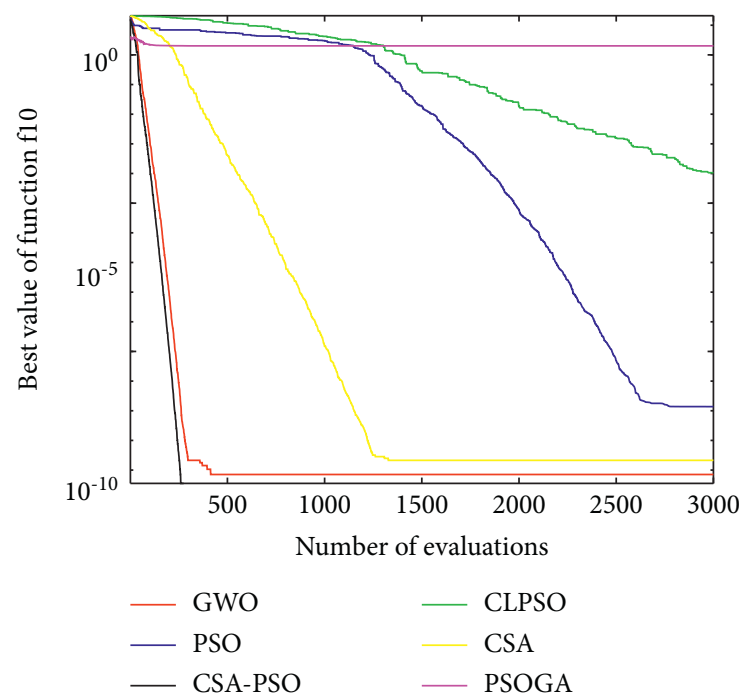

Figure 14: Evolutionary curve of fitness values for $f_{10}$.

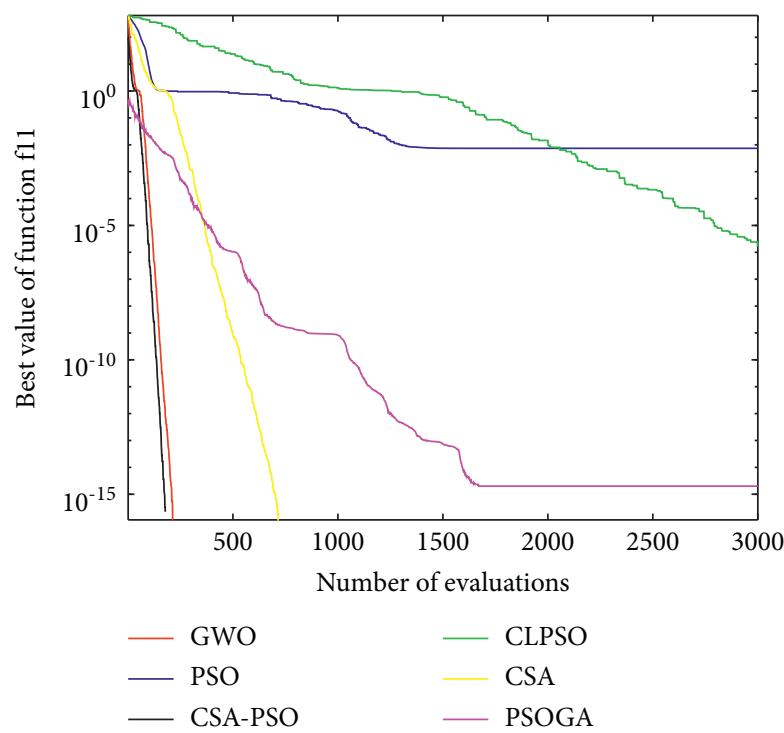

FIgURE 15: Evolutionary curve of fitness values for $f 11$.

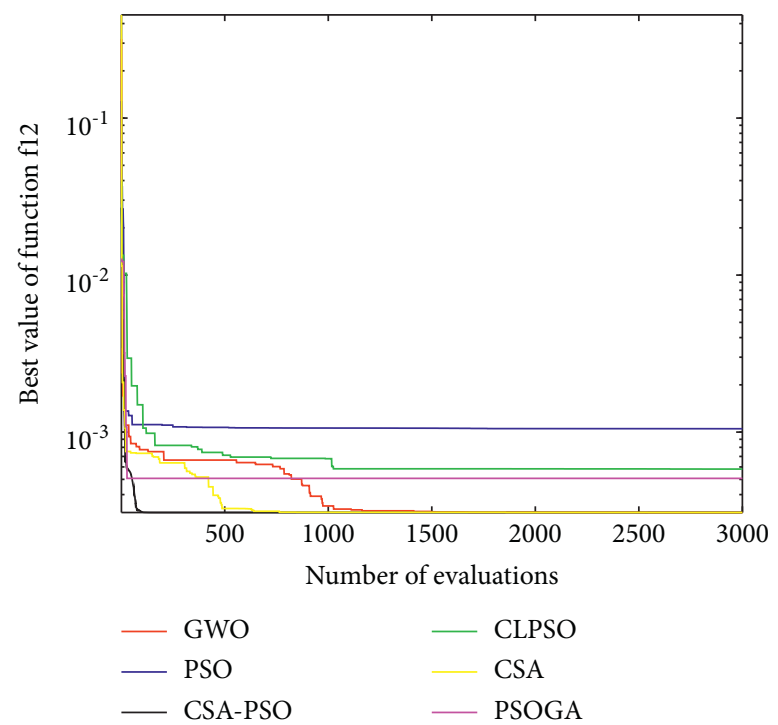

FIgURE 16: Evolutionary curve of fitness values for $f 12$. 


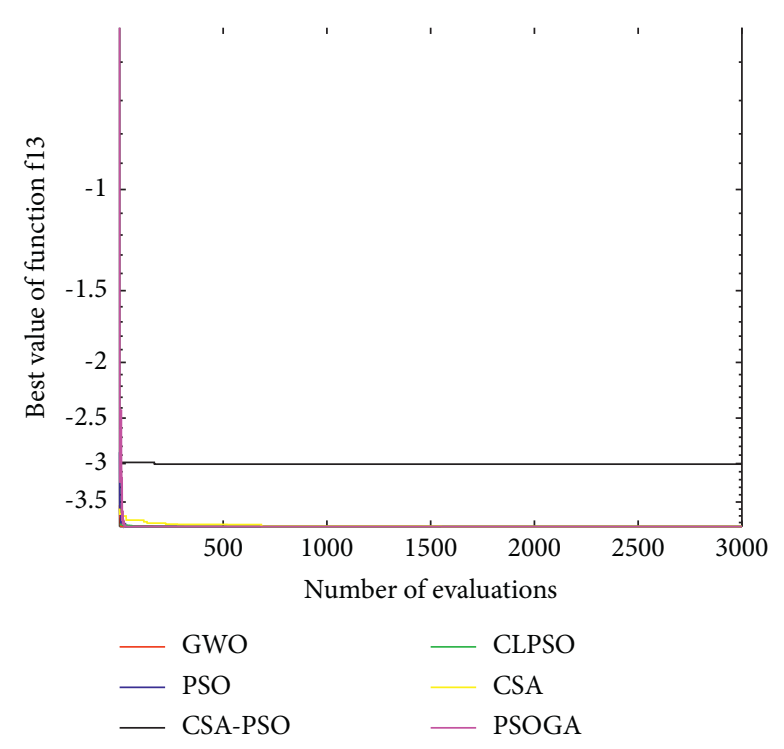

Figure 17: Evolutionary curve of fitness values for $f 13$.

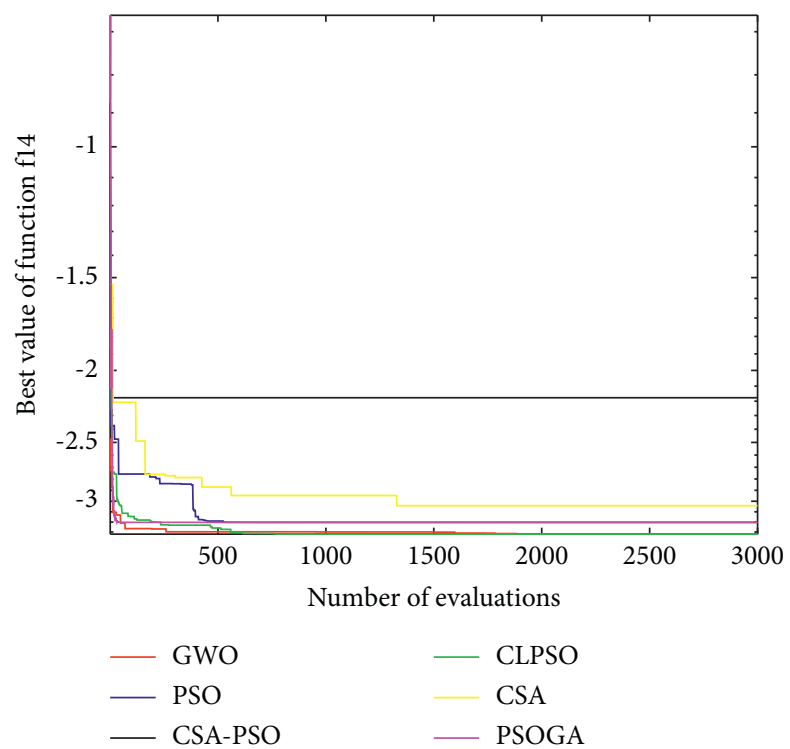

FIgURE 18: Evolutionary curve of fitness values for $f 14$.

while reducing economic cost and environmental cost. The total cost of the CSA-PSO algorithm was $\$ 1789.9$, which improved the economic benefit by $21.5 \%$ compared with the PSO algorithm with the worst optimization result. To sum up, the CSA-PSO algorithm is superior to the other five intelligent algorithms in convergence speed and search accuracy, thus demonstrating the superiority of the CSA-PSO algorithm. Figure 25 describes the convergence curves of six intelligent algorithms for economic and environmental costs. From these data, it can be seen intuitively that CSA-PSO has better search ability and convergence speed than the other five algorithms in the optimal operation of microgrid. 


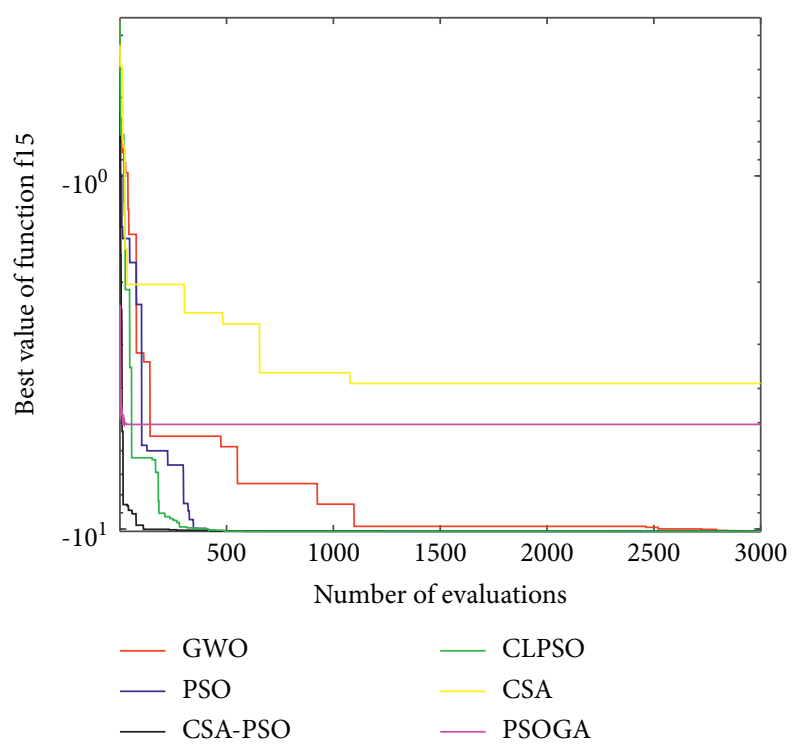

FIgURE 19: Evolutionary curve of fitness values for $f 15$.

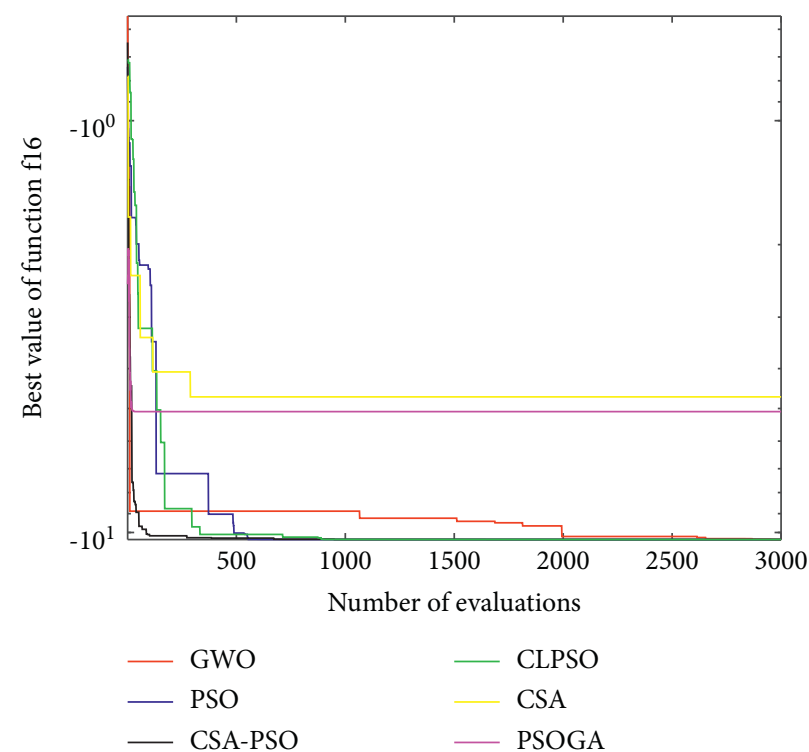

FIgURe 20: Evolutionary curve of fitness values for $f 16$. 


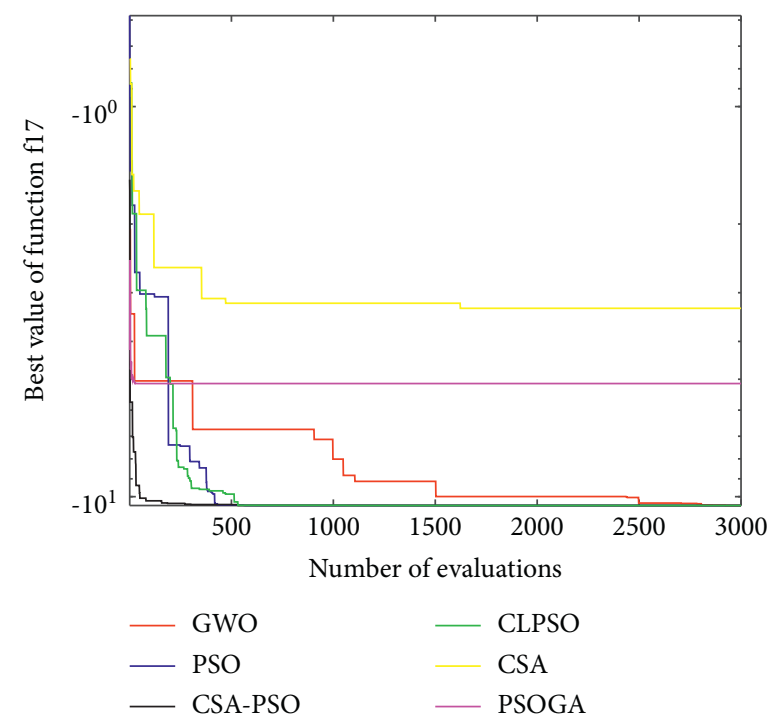

Figure 21: Evolutionary curve of fitness values for $f_{17}$.

TABLE 6: Each algorithm to the function of the optimal result statistics.

\begin{tabular}{|c|c|c|c|c|c|c|c|}
\hline \multirow{2}{*}{ Fun } & \multicolumn{6}{|c|}{ Best } & \multirow{2}{*}{ Optimum } \\
\hline & CSA [11] & PSO [7] & GWO [8] & PSOGA [25] & CLPSO [26] & This article & \\
\hline$f_{1}(x)$ & $2.2040 \mathrm{E}-11$ & $1.3541 \mathrm{E}-01$ & $9.3108 \mathrm{E}-57$ & $9.7886 \mathrm{E}-06$ & $4.5018 \mathrm{E}+03$ & $4.7635 \mathrm{E}-161$ & 0 \\
\hline$f_{2}(x)$ & $2.6320 \mathrm{E}-19$ & $2.9600 \mathrm{E}-13$ & $1.8206 \mathrm{E}-107$ & $2.1438 \mathrm{E}-13$ & $1.4691 \mathrm{E}-05$ & $5.4448 \mathrm{E}-215$ & 0 \\
\hline$f_{3}(x)$ & $6.2822 \mathrm{E}-58$ & $3.0838 \mathrm{E}-46$ & $2.2431 \mathrm{E}-321$ & $6.2394 \mathrm{E}-53$ & $2.4688 \mathrm{E}-17$ & 0 & 0 \\
\hline$f_{4}(x)$ & $2.5246 \mathrm{E}-05$ & $6.3481 \mathrm{E}-02$ & $6.8418 \mathrm{E}-46$ & $1.4422 \mathrm{E}-01$ & $1.6408 \mathrm{E}+01$ & $\mathbf{0}$ & 0 \\
\hline$f_{5}(x)$ & $2.4191 \mathrm{E}+01$ & $2.6202 \mathrm{E}+01$ & $2.7124 \mathrm{E}+01$ & $2.8704 \mathrm{E}+01$ & $3.5616 \mathrm{E}+01$ & $2.2728 \mathrm{E}+01$ & 0 \\
\hline$f_{6}(x)$ & $1.6839 \mathrm{E}+00$ & $9.4726 \mathrm{E}-02$ & $3.6528 \mathrm{E}+00$ & $4.9168 \mathrm{E}-06$ & $7.0937 \mathrm{E}+03$ & $4.2093 \mathrm{E}-01$ & 0 \\
\hline$f_{7}(x)$ & $9.0827 \mathrm{E}-50$ & $1.2395 \mathrm{E}-41$ & $1.1513 \mathrm{E}-309$ & $4.4268 \mathrm{E}-48$ & $3.4583 \mathrm{E}-47$ & 0 & 0 \\
\hline$f_{8}(x)$ & 12555.5 & 12535.6 & 12545.6 & 12456.5 & 12468.5 & 12369.5 & $411.99^{*} \mathrm{n}$ \\
\hline$f_{9}(x)$ & $1.6140 \mathrm{E}+01$ & $2.8853 \mathrm{E}+01$ & $\mathbf{0}$ & $1.0347 \mathrm{E}+02$ & $2.5452 \mathrm{E}-04$ & $\mathbf{0}$ & 0 \\
\hline$f_{10}(x)$ & $2.8422 \mathrm{E}-14$ & $1.4211 \mathrm{E}-14$ & $7.1054 \mathrm{E}-15$ & $1.3404 \mathrm{E}+00$ & $1.6343 \mathrm{E}-04$ & $\mathbf{0}$ & 0 \\
\hline$f_{11}(x)$ & $\mathbf{0}$ & $9.8573 \mathrm{E}-03$ & 0 & $3.4417 \mathrm{E}-15$ & $1.0697 \mathrm{E}-06$ & $\mathbf{0}$ & 0 \\
\hline$f_{12}(x)$ & $3.0750 \mathrm{E}-04$ & $3.5607 \mathrm{E}-04$ & $3.0749 \mathrm{E}-04$ & $3.0749 \mathrm{E}-04$ & $4.2259 \mathrm{E}-04$ & $5.0729 \mathrm{E}-04$ & 0.9980 \\
\hline$f_{13}(x)$ & -3.8573 & -3.8628 & -3.8628 & -3.8628 & -3.8628 & -3.4918 & -1.0316 \\
\hline$f_{14}(x)$ & -2.8790 & -3.3220 & -3.1974 & -3.3220 & -3.3220 & -1.7382 & -3.980 \\
\hline$f_{15}(x)$ & -4.2572 & -10.7532 & -10.7532 & -5.0552 & -10.7532 & -10.7532 & -10.7532 \\
\hline$f_{16}(x)$ & -4.8937 & -10.4029 & -10.4029 & -5.0877 & -10.4029 & -10.4029 & -10.4029 \\
\hline$f_{17}(x)$ & -4.7151 & -10.5634 & -10.5634 & -5.1285 & -10.5634 & -10.5634 & -10.5634 \\
\hline
\end{tabular}

TABLE 7: Statistics of $f_{1} \sim f_{11}$ test results.

\begin{tabular}{|c|c|c|c|c|c|c|c|c|c|}
\hline \multirow{2}{*}{\multicolumn{2}{|c|}{ Test function }} & \multicolumn{4}{|c|}{$D=50$} & \multicolumn{4}{|c|}{$D=100$} \\
\hline & & Best & Mean & Worst & Std & Best & Mean & Worst & Std \\
\hline \multirow{6}{*}{$f_{1}(x)$} & CSA [11] & $5.62 \mathrm{E}-31$ & $1.08 \mathrm{E}+03$ & $1.67 \mathrm{E}+05$ & $8.23 E+03$ & $6.37 \mathrm{E}-14$ & $6.22 \mathrm{E}+02$ & $1.50 \mathrm{E}+05$ & $6.47 \mathrm{E}+03$ \\
\hline & PSO [7] & $2.18 \mathrm{E}-01$ & $7.10 \mathrm{E}+02$ & $9.34 \mathrm{E}+04$ & $4.84 \mathrm{E}+03$ & $9.42 \mathrm{E}-02$ & $5.13 \mathrm{E}+02$ & $1.80 \mathrm{E}+05$ & $5.22 \mathrm{E}+03$ \\
\hline & GWO [8] & $4.02 \mathrm{E}-64$ & $4.78 E+02$ & $1.41 \mathrm{E}+05$ & $4.65 E+03$ & $1.57 \mathrm{E}-51$ & $4.48 \mathrm{E}+02$ & $1.09 \mathrm{E}+05$ & $4.39 \mathrm{E}+03$ \\
\hline & PSOGA [25] & $2.41 \mathrm{E}-06$ & $4.73 E+00$ & $2.79 E+03$ & $6.83 E+01$ & $1.57 \mathrm{E}-06$ & $5.24 \mathrm{E}+00$ & $2.84 \mathrm{E}+03$ & $6.46 \mathrm{E}+01$ \\
\hline & CLPSO [26] & $5.13 E+03$ & $2.27 \mathrm{E}+04$ & $1.20 \mathrm{E}+05$ & $2.73 E+04$ & $7.12 \mathrm{E}+03$ & $2.80 \mathrm{E}+04$ & $1.40 \mathrm{E}$ & $3.07 \mathrm{E}+04$ \\
\hline & CSA-PSO & 0 & $1.36 \mathrm{E}+00$ & $2.38 \mathrm{E}+02$ & $4.54 \mathrm{E}+01$ & $\mathbf{0}$ & $1.38 \mathrm{E}+00$ & $8.78 \mathrm{E}+02$ & $2.42 \mathrm{E}+01$ \\
\hline \multirow{6}{*}{$f_{2}(x)$} & CSA [11] & 0 & $5.28 \mathrm{E}+16$ & & & & & $3.30 \mathrm{E}+46$ & $6.02 \mathrm{E}+44$ \\
\hline & PSO [7] & $1.37 \mathrm{E}-03$ & $1.06 \mathrm{E}+19$ & $3.20 \mathrm{E}+22$ & $5.85 \mathrm{E}+20$ & $6.92 \mathrm{E}-01$ & $2.85 \mathrm{E}+44$ & $8.55 \mathrm{E}+47$ & $1.56 \mathrm{E}+46$ \\
\hline & GWO [8] & $1.33 \mathrm{E}-81$ & $2.63 E+19$ & $7.90 \mathrm{E}+22$ & $1.44 \mathrm{E}+21$ & $1.16 \mathrm{E}-58$ & $1.01 \mathrm{E}+43$ & $3.02 \mathrm{E}+46$ & $5.52 \mathrm{E}+44$ \\
\hline & PSOGA [25] & $1.13 \mathrm{E}-02$ & $1.42 \mathrm{E}+00$ & $2.80 \mathrm{E}+01$ & $4.00 \mathrm{E}+00$ & $1.02 \mathrm{E}-00$ & $9.55 E+00$ & $6.82 \mathrm{E}+01$ & $1.23 \mathrm{E}+01$ \\
\hline & CLPSO [26] & $1.40 \mathrm{E}-02$ & $2.68 E+18$ & $1.47 \mathrm{E}+20$ & $1.92 \mathrm{E}+19$ & $2.74 \mathrm{E}-00$ & $2.99 E+47$ & $1.63 E+49$ & $2.14 \mathrm{E}+48$ \\
\hline & CSA-PSO & 0 & $2.82 \mathrm{E}-01$ & $1.26 \mathrm{E}+01$ & $3.97 \mathrm{E}+00$ & 0 & $2.01 \mathrm{E}+00$ & $1.06 \mathrm{E}+01$ & $1.10 \mathrm{E}+00$ \\
\hline
\end{tabular}


TABle 7: Continued.

\begin{tabular}{|c|c|c|c|c|c|c|c|c|c|}
\hline \multirow{2}{*}{\multicolumn{2}{|c|}{ Test function }} & \multicolumn{4}{|c|}{$D=50$} & \multicolumn{4}{|c|}{$D=100$} \\
\hline & & \multirow{2}{*}{$\frac{\text { Best }}{5.80 \mathrm{E}-56}$} & \multirow{2}{*}{$\frac{\text { Mean }}{6.74 E+02}$} & \multirow{2}{*}{$\frac{\text { Worst }}{1.32 \mathrm{E}+05}$} & \multirow{2}{*}{$\frac{\text { Std }}{6.41 \mathrm{E}+03}$} & \multirow{2}{*}{$\frac{\text { Best }}{2.98 \mathrm{E}-04}$} & \multirow{2}{*}{$\frac{\text { Mean }}{1.34 \mathrm{E}+04}$} & \multirow{2}{*}{$\frac{\text { Worst }}{2.79 \mathrm{E}+05}$} & \multirow{2}{*}{$\frac{\text { Std }}{3.94 E+04}$} \\
\hline$(x)$ & CSA [11] & & & & & & & & \\
\hline & PSO [7] & $1.85 \mathrm{E}-12$ & $3.63 \mathrm{E}+02$ & $1.32 \mathrm{E}+05$ & $5.14 \mathrm{E}+03$ & $1.04 \mathrm{E}-02$ & $9.75 \mathrm{E}+02$ & $2.75 E+05$ & $1.03 \mathrm{E}+04$ \\
\hline & GWO [8] & $1.29 \mathrm{E}-140$ & $2.83 \mathrm{E}+02$ & & $4.42 \mathrm{E}+03$ & $2.40 \mathrm{E}-97$ & $9.43 E+02$ & $2.92 \mathrm{E}+05$ & $1.12 \mathrm{E}+04$ \\
\hline & PSOGA [25] & $9.72 \mathrm{E}-12$ & $7.42 \mathrm{E}-01$ & $2.30 \mathrm{E}+01$ & $2.86 \mathrm{E}+00$ & $185 \mathrm{E}+00$ & $5.36 \mathrm{E}+00$ & $4.69 \mathrm{E}+01$ & $7.54 \mathrm{E}+00$ \\
\hline & CLPSO [26] & $4.81 \mathrm{E}-03$ & $1.06 \mathrm{E}+04$ & $1.28 \mathrm{E}+05$ & $2.57 \mathrm{E}+04$ & $4.41 \mathrm{E}+01$ & $3.89 \mathrm{E}+04$ & $2.51 \mathrm{E}+05$ & $6.65 E+04$ \\
\hline & CSA-PSO & $\mathbf{0}$ & $3.07 \mathrm{E}-01$ & $5.72 \mathrm{E}+00$ & $1.77 \mathrm{E}+00$ & $\mathbf{0}$ & $5.16 \mathrm{E}+00$ & $4.01 \mathrm{E}+01$ & $6.21 \mathrm{E}+00$ \\
\hline \multirow{6}{*}{$f_{4}(x)$} & CSA [11] & 7 & $2.00 \mathrm{E}+00$ & $9.07 \mathrm{E}+01$ & $8.87 \mathrm{E}+00$ & 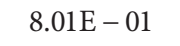 & $4.14 \mathrm{E}+01$ & $9.74 \mathrm{E}+01$ & $3.27 \mathrm{E}+01$ \\
\hline & & & $3.92 \mathrm{E}+00$ & $9.41 \mathrm{E}+01$ & $4.89 \mathrm{E}+00$ & $5.79 \mathrm{E}$ & $1.13 \mathrm{E}+01$ & & \\
\hline & GWO [8] & $7.47 \mathrm{E}-$ & $1.91 \mathrm{E}+00$ & $9.44 \mathrm{E}+01$ & $1.07 \mathrm{E}+01$ & & & $9.72 \mathrm{E}+01$ & $5 \mathrm{E}+01$ \\
\hline & PSOGA [25] & $8.89 \mathrm{E}-01$ & $9.78 \mathrm{E}-01$ & $1.43 \mathrm{E}+00$ & $7.97 \mathrm{E}-02$ & $1.98 \mathrm{E}+00$ & $1.99 \mathrm{E}+00$ & & $0 \mathrm{E}-02$ \\
\hline & CLP & & & & & & & & \\
\hline & CSA-PSO & $\mathbf{0}$ & $1.11 \mathrm{E}-01$ & $3.66 \mathrm{E}+$ & $1.50 \mathrm{E}+00$ & $\mathbf{0}$ & $1.30 \mathrm{E}$ & $4.12 \mathrm{E}$ & $1.62 \mathrm{E}+00$ \\
\hline \multirow{6}{*}{$f_{5}(x)$} & & & & & & & & & \\
\hline & & & & & & & & & \\
\hline & GWO [8] & & $\mathrm{E}+05$ & $5.50 \mathrm{E}+08$ & & & & & $4.62 \mathrm{E}+07$ \\
\hline & PSOGA [25] & $4.48 \mathrm{E}+01$ & $1.50 \mathrm{E}+02$ & $2.54 \mathrm{E}+03$ & $2.32 \mathrm{E}+02$ & $2.93 \mathrm{E}$ & $6.71 \mathrm{E}+02$ & & \\
\hline & CLPS & & & & & & & & \\
\hline & CSA-PSO & & & & & & & & \\
\hline \multirow{6}{*}{$f_{6}(x)$} & & & & & & & & & \\
\hline & & & & & & & & & \\
\hline & GW & & & & & & & & \\
\hline & PSOGA [25] & 66 & 0 & 2 & 2 & 1. & 1 & & \\
\hline & CLPSO [26] & & & & & & & & \\
\hline & & & & & & & & & \\
\hline \multirow{6}{*}{$f_{7}(x)$} & & & & & & & & & \\
\hline & & & & & & & & & \\
\hline & GWO [8] & $9 E-233$ & $9 \mathrm{E}-01$ & $3.83 \mathrm{E}+02$ & 9. & $4.95 \mathrm{E}-162$ & & & $\mathrm{E}+01$ \\
\hline & PSOGA [25] & $2 E-13$ & Q E, 0 & & 4 & $1.17 \mathrm{E}+00$ & & & \\
\hline & & & & & & & & & \\
\hline & CSA-PSO & 0 & -03 & & & $\mathbf{0}$ & & 1 & \\
\hline \multirow{6}{*}{$f_{8}(x)$} & & & $E+03$ & & & & & & \\
\hline & & & & & & & & & \\
\hline & GWO [8] & $-8.19 E+03$ & $-5.25 E+03$ & $-2.67 \mathrm{E}+$ & & & & & \\
\hline & PSOGA [25] & $7 \mathrm{E}+02$ & & & & & & & \\
\hline & {$[26]$} & +04 & -04 & -2 & 5 & -4 & -2 & -1 & +04 \\
\hline & CSA-PSO & $8 \mathrm{E}+04$ & $-2.03 E+04$ & $E+03$ & $8 \mathrm{E}+01$ & & $2 \mathrm{E}+04$ & $9 \mathrm{E}+03$ & 2. \\
\hline & & & & & & & & & \\
\hline & & $5 \mathrm{E}+01$ & & & & . & & & \\
\hline & GWO [8] & $\mathbf{0}$ & & & & 0 & & & +02 \\
\hline$f_{9}(x)$ & $A[25]$ & $5 E+01$ & & & & & & & \\
\hline & CLPSO [26] & $8 \mathrm{E}-01$ & $\mathrm{E}+02$ & $2 E+02$ & $2.06 \mathrm{E}+02$ & $7.27 \mathrm{E}+$ & $2 \mathrm{E}+02$ & $1.70 \mathrm{E}+03$ & $4.54 \mathrm{E}+02$ \\
\hline & CSA-PSO & $\mathbf{0}$ & $6 \mathrm{E}+00$ & $4.90 \mathrm{E}+02$ & $3.07 \mathrm{E}+01$ & $\mathbf{0}$ & & $9.95 \mathrm{E}+02$ & $6.62 \mathrm{E}+01$ \\
\hline & & & & & & & & & \\
\hline & & & & & & & & & \\
\hline & GWO [8] & $\mathrm{DE}-14$ & $8 D-01$ & $6 \mathrm{E}+01$ & $1.70 \mathrm{E}+00$ & $1.42 \mathrm{E}-14$ & $3.34 \mathrm{E}-01$ & $2.10 \mathrm{E}+01$ & $2.16 \mathrm{E}+00$ \\
\hline & PSOGA [25] & & $5 \mathrm{E}+00$ & $0 \mathrm{E}+00$ & & & & $3 E+00$ & $3.90 \mathrm{E}-01$ \\
\hline & CLPSO [26] & $7 \mathrm{E}-02$ & $3 E+00$ & $04 \mathrm{E}+01$ & $6.93 \mathrm{E}+00$ & $3.06 \mathrm{E}+00$ & $1.12 \mathrm{E}+01$ & $2.10 \mathrm{E}+01$ & $6.15 E+00$ \\
\hline & CSA-PSO & $\mathbf{0}$ & $7.36 \mathrm{E}-02$ & $1.52 \mathrm{E}+01$ & $0.25 \mathrm{E}-01$ & $\mathbf{0}$ & $7.65 E-02$ & $1.48 \mathrm{E}+01$ & $8.31 \mathrm{E}-01$ \\
\hline & [11] & $6 \mathrm{~F}-$ & $98 F+00$ & $118 \mathrm{~F}+03$ & $401 \mathrm{~F}+01$ & - & $119 F+01$ & $2.70 \mathrm{E}+03$ & $110 \mathrm{~F}+$ \\
\hline & O [7] & $5 \mathrm{E}-$ & $\Gamma_{1}$ & $E+03$ & 9. & $1.43 \mathrm{E}-$ & 01 & $7 E+03$ & $E+02$ \\
\hline & GWO [8] & $\mathbf{0}$ & $3 \mathrm{E}+00$ & $1 E+03$ & $4.09 \mathrm{E}+01$ & $\mathbf{0}$ & $9.23 E+00$ & $2.46 \mathrm{E}+03$ & $1.01 E+02$ \\
\hline & PSOGA [25] & $1 E-03$ & $2.14 \mathrm{E}-02$ & $5.92 \mathrm{E}-01$ & $6.49 \mathrm{E}-02$ & $1.62 \mathrm{E}-03$ & $7.37 \mathrm{E}-02$ & $6.80 \mathrm{E}-01$ & $1.24 \mathrm{E}-01$ \\
\hline & CLPSO [26] & $9.56 \mathrm{E}-03$ & $8.75 E+01$ & $1.18 \mathrm{E}+03$ & $2.07 \mathrm{E}+02$ & $1.30 \mathrm{E}+00$ & $3.51 \mathrm{E}+02$ & $2.44 \mathrm{E}+03$ & $6.04 E+02$ \\
\hline & CSA-PSO & $\mathbf{0}$ & $\mathbf{0}$ & $\mathbf{0}$ & $\mathbf{0}$ & $\mathbf{0}$ & $5.87 \mathrm{E}-02$ & $3.45 \mathrm{E}-01$ & $1.05 \mathrm{E}-01$ \\
\hline
\end{tabular}


TABLE 8: Specific parameters of the micropower supply.

\begin{tabular}{lcccc}
\hline Power supply type & Lower power limit $(\mathrm{KW})$ & Power limit $(\mathrm{KW})$ & Operating cost $(\$ / \mathrm{KWh})$ & Fuel cost $(\$ / \mathrm{KWh})$ \\
\hline PV & 0 & 50 & 0.0103 & - \\
WT & 0 & 75 & 0.0450 & - \\
FC & 0 & 65 & 0.0293 & 0.2435 \\
MT & 0 & 65 & 0.0419 & 0.4090 \\
ICE & 0 & 50 & 0.0125 & 0.6031 \\
\hline
\end{tabular}

TABle 9: Pollutant discharge parameters.

\begin{tabular}{lccccc}
\hline Type of pollutant & Cost of treatment $(\$ / \mathrm{Kg})$ & $\mathrm{FC}(\mathrm{Kg} / \mathrm{kwh})$ & $\mathrm{MT}(\mathrm{Kg} / \mathrm{kwh})$ & $\mathrm{ICE}(\mathrm{Kg} / \mathrm{kwh})$ & $\mathrm{Grid}(\mathrm{Kg} / \mathrm{kwh})$ \\
\hline $\mathrm{CO}_{2}$ & 0.088 & 1.596 & 1.4 & 1.078 & 2.3 \\
\hline $\mathrm{NO}_{\mathrm{X}}$ & 26.46 & 0.440 & 0.030 & 21.8 & 3.6 \\
\hline $\mathrm{SO}_{2}$ & 6.237 & 0.008 & 0.006 & 0.454 & 4.54 \\
\hline
\end{tabular}

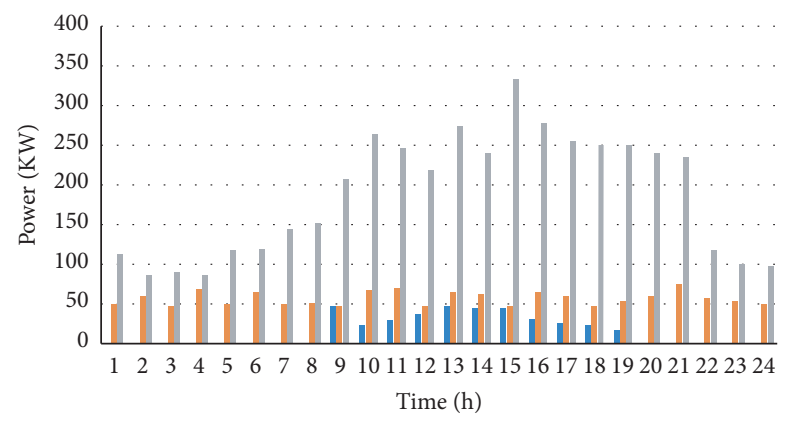

$$
\begin{aligned}
& \text { - PV } \\
& -\mathrm{WT} \\
& \square \text { load }
\end{aligned}
$$

FIgURE 22: PV and WT output power and load requirements.

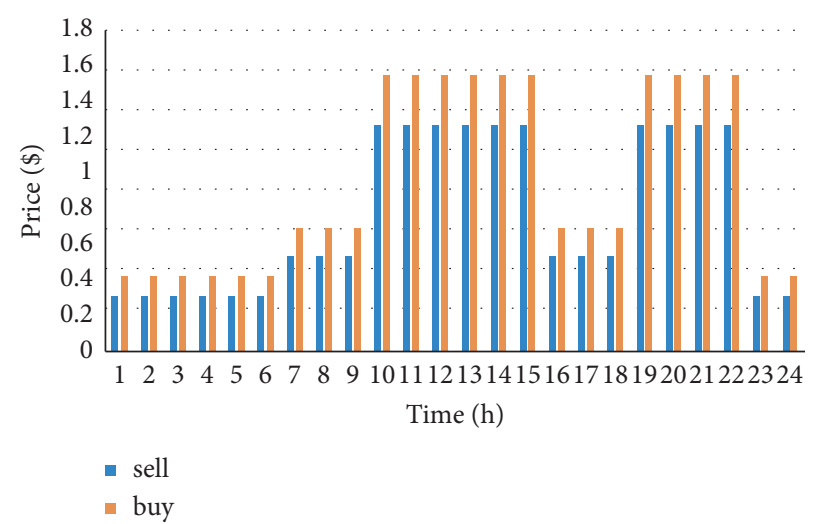

FIGURE 23: The price of buying and selling electricity. 


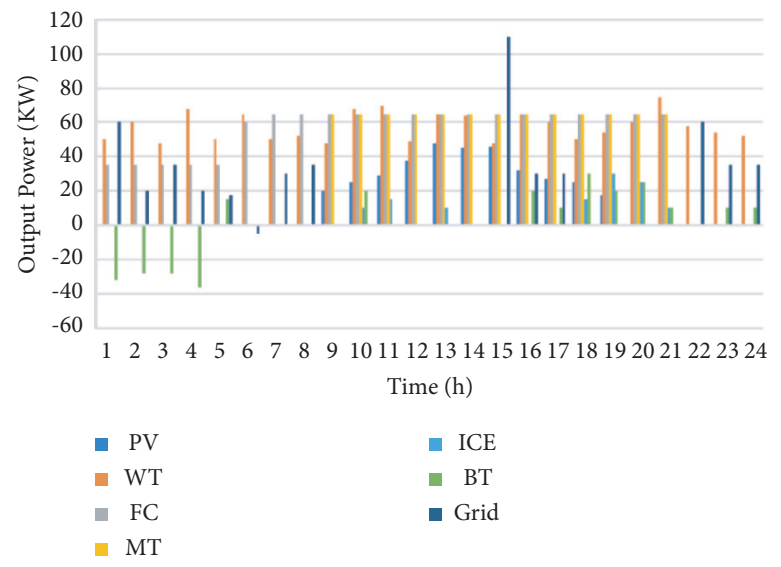

Figure 24: Output results for each micropower source.

TABle 10: Comparison of consequences.

\begin{tabular}{|c|c|c|c|c|c|c|}
\hline Algorithm & CSA-PSO & CSA [11] & PSO [7] & CLPSO [26] & PSOGA [25] & GWO [8] \\
\hline Cost (\$) & 1789.90 & 1994.0 & 2176.2 & 1822.1 & 1827.3 & 2063.2 \\
\hline CPU time (s) & $2.0651 \mathrm{~s}$ & $3.2625 \mathrm{~s}$ & $3.8658 \mathrm{~s}$ & $3.9854 \mathrm{~s}$ & $3.0582 \mathrm{~s}$ & $4.0236 \mathrm{~s}$ \\
\hline
\end{tabular}

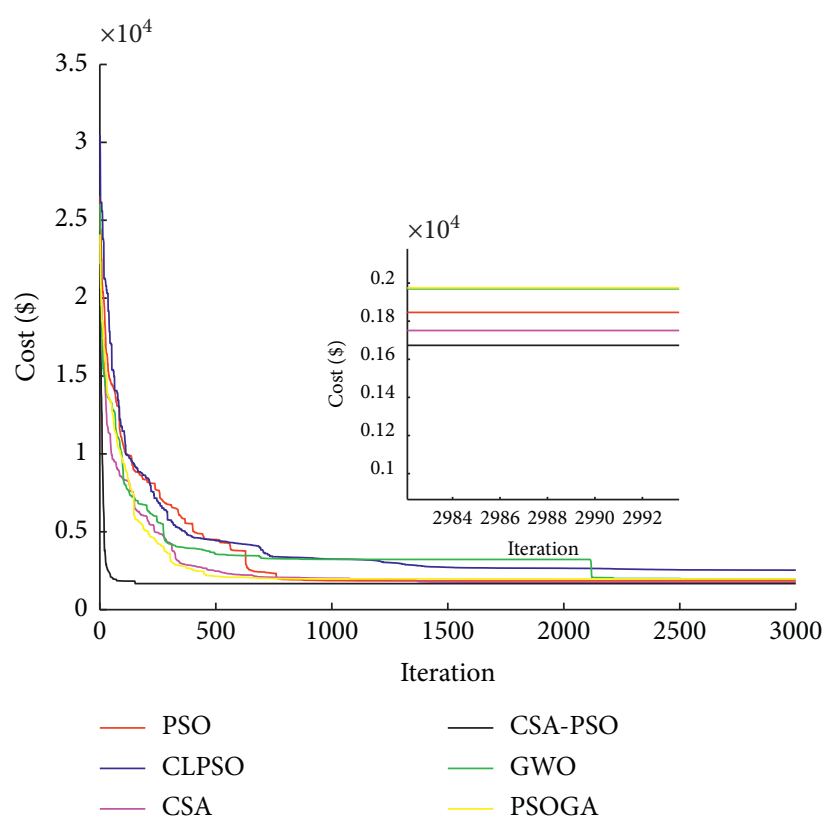

FIgURE 25: Optimization search results for each algorithm.

\section{Discussion and Conclusions}

Based on the shortcomings of the crow search algorithm, this article proposes an improved crow search algorithm (CSA-PSO) to understand the optimization mechanism of the particle swarm optimization (PSO). Major improvements are as follows: (1) in order to avoid the crows in the process of search blind choice, every raven when searching the optimal solution, to share information with other partners in the population, so as to find the global optimal solution in the population as a whole has the best individual extremum, according to the population information update crow iteration, so as to improve development ability; and (2) the levy flight strategy was introduced to improve the single search mechanism of CSA and effectively avoid falling into local optimum. The experimental results show that the algorithm is better than other swarm intelligence algorithms in search accuracy and convergence speed. At the same time, the algorithm is applied to energy dispatching of microgrid. Taking the lowest economic cost and the best environmental benefit of microgrid as the objective function, a mathematical model is established to reduce the total operating cost of microgrid by reasonably arranging the output of micropower. The validity of the algorithm is verified. 


\section{Data Availability}

The data that support the findings of this study are available from the corresponding author upon reasonable request.

\section{Consent}

Not applicable

\section{Conflicts of Interest}

The authors declare that they have no conflicts of interest.

\section{Authors' Contributions}

Zhao is mainly responsible for the experiments, Chen and Wen are responsible for organizing the data, and Zhang is responsible for writing. All authors have read and agreed to the published version of the manuscript.

\section{Acknowledgments}

This work was supported by the Foshan Scientific and Technological Innovation Team Fund, Project no. FS0AAKJ91944020062.

\section{References}

[1] J. Driesen and F. Katiraei, "Design for distributed energy resources," IEEE Power and Energy Magazine, vol. 6, no. 3, pp. 30-40, 2008.

[2] W.-J. Ma, J. Wang, V. Gupta, and C. Chen, "Distributed energy management for networked microgrids using online ADMM with regret," IEEE Transactions on Smart Grid, vol. 9, no. 2, pp. 847-856, 2018.

[3] Z. Wang, B. Chen, J. Wang, M. M. Begovic, and C. Chen, "Coordinated energy management of networked microgrids in distribution systems," IEEE Transactions on Smart Grid, vol. 6, no. 1, pp. 45-53, 2015.

[4] A. Khodaei, "Resiliency-oriented microgrid optimal scheduling," IEEE Transactions on Smart Grid, vol. 5, no. 4, pp. 1584-1591, 2014.

[5] E. Unamuno and B. Jon-Andoni, "Hybrid ac/dc microgridspart I: review and classification of topologies," Renewable \& Sustainable Energy Reviews, vol. 52, pp. 521251-521259, 2015.

[6] E. Unamuno and B. Jon-Andoni, "Hybrid Ac/dc microgrids part II: review and classification of control strategies," Renewable \& Sustainable Energy Reviews, vol. 53, pp. 521123-521134, 2015.

[7] J. Kennedy and R. Eberhart, "Particle swarm optimization," in Proceedings of the ICNN'95 -International Conference on Neural Networks, Glasgow, UK, November 1995.

[8] S. Mirjalili, S. M. Mirjalili, and A. Lewis, "Grey wolf optimizer," Advances in Engineering Software, vol. 69, pp. 46-61, 2014.

[9] F. Zhao, X. He, and L. Wang, "A two-stage cooperative evolutionary algorithm with problem-specific knowledge for energy-efficient scheduling of No-wait flow-shop problem," IEEE Transactions on Cybernetics, vol. 51, no. 11, pp. 5291-5303, 2021, Nov. 2021.

[10] F. Zhao, R. Ma, and L. Wang, "A self-learning discrete jaya algorithm for multiobjective energy-efficient distributed No- idle flow-shop scheduling problem in heterogeneous factory system," IEEE Transactions on Cybernetics, vol. 12, 2021.

[11] A. Askarzadeh, "A novel metaheuristic method for solving constrained engineering optimization problems: crow search algorithm," Computers \& Structures, vol. 169, pp. 1-12, 2016.

[12] A. Askarzadeh, "'Capacitor placement in distribution systems for power loss reduction and voltage improvement: a new methodology," "IET Generation, Transmission \& Distribution, vol. 10, no. 14, pp. 3631-3638, 2016.

[13] A. Meddeb, N. Amor, and M. Abbes, “A novel approach based on crow search algorithm for solving reactive power dispatch problem," Energies, vol. 11, 2018.

[14] A. Y. Abdelaziz and A. Fathy, "A novel approach based on crow search algo"thm for optimal selection of conductor size in radial distribution networks," Engineering Science Technology an International Journal, vol. 20, no. 2, 2017.

[15] R. M. Rizk-Allah, A. E. Hassanien, and S. Bhattacharyya, "Chaotic crow search algorithm for fractional optimization problems," "Applied Soft Computing, vol. 71, pp. 1161-1175, 2018.

[16] S. Hinojosa, D. Oliva, E. Cuevas, G. Pajares, O. Avalos, and J. Gálvez, "Improving multi-criterion optimization with chaos: a novel multi-objective chaotic crow search algorithm," "Neural Computing \& Applications, vol. 29, no. 8, pp. 319-335, 2018.

[17] D. Gupta, S. Sundaram, A. Khanna, A. Ella Hassanien, and V. H. C. de Albuquerque, "“'Improved diagnosis of Parkinson's disease using optimized crow search algorithm," "Computers \& Electrical Engineering, vol. 68, pp. 412-424, 2018.

[18] S. H. I. Zhajun, L. I. Qishen, and S. Zhang, "Improved crow search algorithm with Inertia weight factor and roulette wheel selection scheme," in Proceedings of the 10th International Symposium on Computational Intelligence and Design (ISCID), Washington, D.C., USA, May 2017.

[19] H. Ella, R. Rizk-Allah, and E. Mohamed, "A hybrid crow search algorithm based on rough searching scheme for solving engineering optimization problems," Journal of Ambient Intelligence and Humanized Computing, vol. 27, 2018.

[20] Q. U. Chiwen and F. U. Yanming, "Crow search algorithm based on neighborhood search of non-inferior solution set," IEEE Access, vol. 7, pp. 52871-52895, 2019.

[21] Y. Miao, Research on Optimal Dispatching of Microgrid, North China Electric Power University, Beijing, China, 2013.

[22] X. Xin Yao, Y. Yong Liu, and G. M. Guangming Lin, "Evolutionary programming made faster," IEEE Transactions on Evolutionary Computation, vol. 3, no. 2, pp. 82-102, 1999.

[23] K. Tang, ““Benchmark functions for the CEC'2008 special session and competition on large scale global optimization," in Nature Inspired Computation and Applications Laboratory, pp. 1-24, USTC, Anhui Sheng, China, 2007.

[24] L.-Y. Tseng and C. Chen, "'Multiple trajectory search for large scale global optimization," in Proceedings of the IEEE Congress on Evolutionary Computation, pp. 3052-3059, Hong Kong, China, June 2008.

[25] H. Wang, W. Cai, and Y. Wang, "Optimization of a hybrid ejector air conditioning system with PSOGA," Applied Thermal Engineering: Design, Processes, Equipment, Economics, vol. 112, pp. 1121474-1121486, 2017.

[26] Yu Xue, X. Hu, and Y. Lin, "Integrated learning particle swarm optimization algorithm with evaluation mechanism," Computer Engineering and Design, vol. 3, pp. 753-758, 2015. 